\title{
Atmospheric forcing on the Canadian Arctic Archipelago freshwater outflow and implications for the Labrador Sea variability
}

\author{
Marie-Noëlle Houssais $^{1}$ and Christophe Herbaut ${ }^{1}$ \\ Received 7 April 2010; revised 25 November 2010; accepted 21 December 2010; published 12 March 2011.
}

[1] The variability of the freshwater export through the Canadian Arctic Archipelago

(CAA) is analyzed using a hindcast simulation forced by surface atmospheric forcing from the ERA40 reanalysis (1958-2001). Although the two channels representing the archipelago in the model are both sensitive to the along-channel sea surface height (SSH) gradient, they appear to have very distinct behaviors. The outflow to Lancaster Sound is shown to be largely controlled by the magnitude of the upstream SSH gradient across McClure Strait. The gradient shows a close link to the wind stress curl in the western Arctic but also to a large-scale SSH anomaly pattern which has a strong signal over the shelf to the south of McClure Strait. The latter has, however, little statistical connection to the SSH variability in the Beaufort Gyre. By contrast, the outflow through Nares Strait responds preferentially to $\mathrm{SSH}$ variations in the northern Baffin Bay which are remotely forced by air-sea heat exchanges in the Labrador Sea. The variability is largely coherent between the two outflows and is controlled by a dipolar atmospheric pattern reminiscent of the North Atlantic/Arctic Oscillation. When entering the subpolar gyre, the CAA freshwater outflow remains confined to the Labrador shelf with little impact on the salinity of the interior Labrador Sea and potentially on the convection. The latter is represented by a distinct mode of salinity variability in the western subpolar gyre which is rather influenced by the variability of the sea ice export through Fram Strait.

Citation: Houssais, M.-N., and C. Herbaut (2011), Atmospheric forcing on the Canadian Arctic Archipelago freshwater outflow and implications for the Labrador Sea variability, J. Geophys. Res., 116, C00D02, doi:10.1029/2010JC006323.

\section{Introduction}

[2] The variability of the freshwater export from the Arctic Ocean is a major concern in view of its potential impact on the meridional overturning circulation [Jungclaus et al., 2005]. There are two main passages for the freshwater to flow from the Arctic to the North Atlantic: the Fram Strait between Greenland and Svalbard and the channels of the Canadian Arctic Archipelago (CAA) to the west of Greenland (Figure 1). The freshwater outflows as both solid ice and liquid water. The sea ice component is mainly exported through Fram Strait where the longest time series of direct observations reported so far indicates a mean export of about 0.75 Sv over the period 1990-1999 [Widell et al., 2003]. In comparison, observations made in Lancaster Sound and Nares Strait [Kwok, 2005, Agnew et al., 2008] reveal a 1 order of magnitude lower sea ice volume export to Baffin Bay through the CAA. The liquid part of the freshwater export from the Arctic occurs through both Fram Strait and the different passages of the CAA (see Figure 1 for the locations

\footnotetext{
${ }^{1}$ LOCEAN, UMR 7159, CNRS/UPMC/IRD/MNHN, Université Pierre et Marie Curie, Paris, France.

Copyright 2011 by the American Geophysical Union. 0148-0227/11/2010JC006323
}

of the different passages). The contribution of the CAA has long been assumed to be small until measurements in Lancaster Sound (since 1998) and along Nares Strait (since 2003) revealed a substantial volume export of about 0.6 $0.9 \mathrm{~Sv}$ in each of these two passages [Prinsenberg and Hamilton, 2005; Münchow and Melling, 2008]. An additional volume transport of $0.3 \mathrm{~Sv}$ was also calculated through the Cardigan Strait-Hell Gate passages [Melling et al., 2008]. The freshwater outflow associated with these transports has been estimated to approximately $75 \mathrm{mSv}$ (referred to salinity $\mathrm{S}_{\mathrm{ref}}=34.80$ ) by Melling et al. [2008] and therefore appears to be on same order of magnitude as the freshwater imported through Bering Strait [Dickson et al., 2007]. It should also be of comparable magnitude with the liquid freshwater export through Fram Strait. Based on current meter measurements and on the flux of meteoric water calculated by Meredith et al. [2001], Serreze et al. [2006] indeed extrapolated the annual mean liquid freshwater flux of the upper waters in Fram Strait to be $2400 \pm 400 \mathrm{~km}^{3}$ for 1997 and 1998, i.e., $76 \pm 13 \mathrm{mSv}$. More recently, de Steur et al. [2009] calculated a liquid freshwater flux of roughly $40 \mathrm{mSv}$ in this strait which could be extrapolated to $66 \mathrm{mSv}$ to account for the part flowing over the East Greenland shelf. Values of the freshwater fluxes through the CAA calculated by Melling et al. [2008] are consistent with Cuny et al.'s [2005] estimate of $92 \pm 34 \mathrm{mSv}$ 


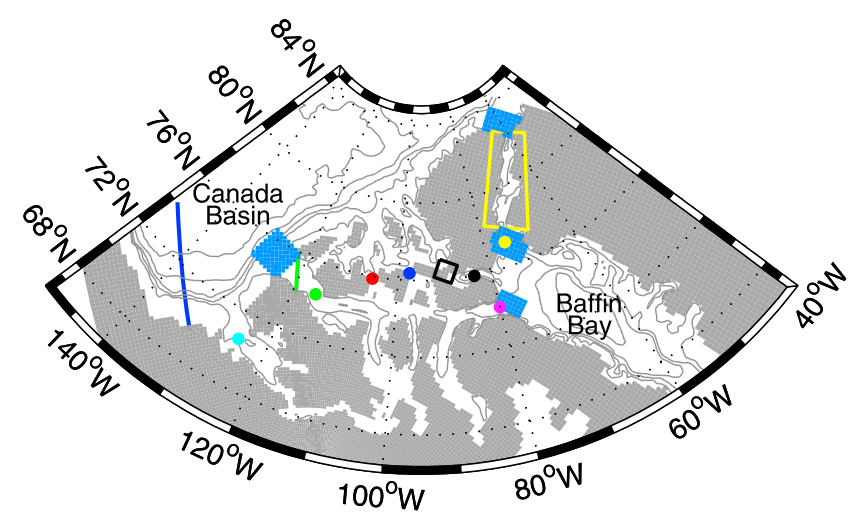

Figure 1. Model bathymetry in the Canadian Arctic Archipelago. Also shown as colored dots are locations of various channels of the CAA: Amundsen Gulf(cyan), McClure Strait (green), Byam Martin Strait (red), Penny Channel (blue), Lancaster Sound (magenta), Jones Sound (black), and Smith Sound (yellow). The yellow and black boxes define Nares Strait and Cardigan Strait and Hell Gate, respectively. The blue and green lines indicate sections referred to in text as the Beaufort Sea and the McClure Strait sections, respectively. The blue boxes define areas over which SSH have been averaged to define relevant time series.

for the mean liquid freshwater flux through Davis Strait based on current meter measurements at moorings deployed between September 1987 and August 1990 across the strait. Model simulations performed by Köberle and Gerdes [2007] provide similar mean values for the two passages, confirming the growing evidence that the CAA plays an important role in the arctic freshwater outflow to the North Atlantic.

[3] With regards to the variability of the export through the CAA, relevant observational time series are lacking and results from model simulations do not agree on whether the export would be less or more variable than in Fram Strait [Köberle and Gerdes, 2007; Jahn et al., 2010a]. In most simulations, the variability of the liquid freshwater outflow through the CAA appears to be largely controlled by ocean velocity anomalies [Lique et al., 2009; Jahn et al., 2010a, 2010b; Koenigk et al., 2007] with freshwater concentration anomalies adding a smaller contribution. More generally, a number of studies have highlighted a link between the variability of the liquid freshwater export from the Arctic and the variability of the Arctic freshwater reservoir. Proshutinsky et al. [2002] suggested that when a cyclonic wind forcing prevails and less freshwater is stored in the Beaufort Gyre, the transport of freshwater to the North Atlantic should be enhanced. The variability of the freshwater storage would be forced by changes in the Ekman pumping occurring on seasonal [Yang and Comiso, 2007] and interannual [Proshutinsky et al., 2009] time scales. The link between the simulated freshwater storage in the Beaufort Sea and the liquid freshwater export through the CAA appears to originate in a shift of the Beaufort Gyre freshwater reservoir which is displaced toward the North American coast during periods of increased export [Jahn et al., 2010a, 2010b]. Such a shift is altogether responsible for sea surface height ( $\mathrm{SSH}$ ) changes in the Beaufort Sea which are associated with changes in the water volume exported through the CAA and, to a lesser extent, for changes in the freshwater concentration of the exported water [Jahn et al., 2010b]. The exact mechanisms underpinning the relationship between the Beaufort Sea and the CAA variability however was not fully investigated. Moreover, the relative impact of the SSH variability in the Beaufort Sea compared with that of the SSH variability downstream of the CAA, in Baffin Bay, needs to be ascertain as different models seem to lead to different conclusions [Kliem and Greenberg, 2003; Jahn et al., 2010a, 2010b].

[4] Idealized modeling experiments have investigated the role of the atmospheric forcing variability, as represented by the North Atlantic Oscillation (NAO) or Arctic Oscillation (AO), in driving Arctic Ocean changes. Note that the impacts of these two modes are expected to be very similar as they correlate at 0.95 [Deser, 2000]. These experiments suggest that periods of persistent positive NAO indices such as the one which occurred between 1989 and the mid-1990s have the potential to force important changes in the Arctic freshwater export. In particular, when the Arctic Ocean is forced by constant positive NAO-like atmospheric anomalies, the excess of freshwater appears to be mostly exported through the CAA [Condron et al., 2009; Houssais et al., 2007]. Consistently, Jahn et al. [2010a] find a significant correlation $(0.54)$ between the $\mathrm{AO}$ and the freshwater export through the CAA in the following year.

[5] In the present study we try to identify the mechanisms driving the freshwater export through the CAA and their link with the atmospheric forcing. We will show that, in agreement with earlier studies, the variability of the freshwater outflow through the CAA is primarily controlled by the volume export which has a strong statistical link to the SSH distribution. The SSH anomalies associated with the volume export variability show a dipolar pattern with two distinct centers of action, one located in the western Arctic and the other in the western subpolar North Atlantic. A specific goal of the present study has been to investigate the physical mechanisms underlying this statistical relationship. Dedicated model sensitivity experiments have been used to demonstrate that these mechanisms have strong link to the NAO. In particular, it will be shown that NAO-like wind stress anomalies should primarily control the northern center of action of the dipole while NAO-like heat flux anomalies mostly maintain the southern one.

[6] The paper is organized as follows. Section 2 describes the model used for the analysis and the experimental setup of the simulations. Section 3 focuses on the results of a 44 year long hindcast experiment. After a brief validation of the simulated arctic freshwater export to the North Atlantic, the variability of the export through the CAA is presented and the driving mechanisms analyzed. In section 4 , the different mechanisms are investigated in the light of the model response to prescribed NAO-like forcing anomalies. The implications for the variability of the surface salinity in the Labrador Sea are briefly addressed in section 5. In section 6, the results are discussed in relation to earlier analyses and section 7 presents some conclusions.

\section{Model Design and Experimental Setup}

[7] The ice-ocean model is based on NEMO version 1.9 [Madec, 2008] including the LIM2 sea ice model. The equations are discretized on 46 vertical levels with thickness varying from $6 \mathrm{~m}$ for the top layer to roughly $250 \mathrm{~m}$ at the 
deepest model level. Partial steps are used in order to better represent the effects of bottom topography. Isopycnal tracer mixing is parameterized by a Laplacian operator while a biharmonic operator is used for horizontal viscous effects. A turbulent kinetic energy closure scheme is used for vertical mixing of momentum and tracers which explicitly calculates the evolution of the turbulent kinetic energy.

[8] The domain encompasses the Arctic Ocean and the Atlantic Ocean, with open boundaries at $30^{\circ} \mathrm{S}$ in the Atlantic and $50^{\circ} \mathrm{N}$ in the Pacific along which the velocity and tracer distributions are prescribed from the monthly climatology of a global simulation. The model grid has horizontal resolution varying from $22 \mathrm{~km}$ in the Arctic (including the CAA) to $50 \mathrm{~km}$ at the equator. The Arctic Ocean connects to the Baffin Bay by two channels, the western channel connecting Amundsen Bay and McClure Strait to Lancaster Sound and the eastern channel connecting to Smith Sound through Nares Strait (Figure 1). The Cardigan Strait and Hell Gate are closed and the corresponding outflow to Baffin Bay occurs through Lancaster Sound. There is no connection between the CAA and the Hudson Bay.

[9] The model is initialized from rest with initial temperature and salinity distributions from the PHC 3.0 global ocean climatology updated from Steele et al. [2001]. Except for the precipitation, the surface forcing is based on daily atmospheric fields from the ERA40 reanalysis (1958-2001) [Uppala et al., 2005]. Turbulent heat fluxes are computed using Large and Yeager's [2004] bulk formulae with daily dew point temperature, surface air temperature (SAT), wind speed and surface pressure as main atmospheric inputs. With regards to precipitation, while the overall ERA40 total precipitation appears to be realistic in comparison with the CORE data set [Large and Yeager, 2004], we found that the distribution between the solid and liquid contributions was suspicious in the Arctic. Therefore, the two precipitation components and their total have been replaced by the CORE data. Regional corrections have also been made to improve the radiation flux over the North Atlantic and the SAT over the Arctic. All these corrections have been applied to the annual climatological cycle obtained by averaging the daily fields over the 44 years of the reanalysis, while the field anomalies (obtained by subtracting this climatology from the original daily fields) are kept unchanged. Over the Atlantic Ocean, the ISCCP radiation climatology [Rossow and Schiffer, 1999] is used instead of ERA40, while in the Arctic Ocean (north of Fram Strait) the ERA40 SAT climatology is replaced by the IABP climatology [Rigor et al., 2000] in order to remove undesirable positive summer SAT values. The river runoff is prescribed from the R-ArcticNET monthly climatology (http://www.R-ArcticNET.sr.unh.edu). The salinity in the $6 \mathrm{~m}$ top layer is restored to the PHC climatology with a time scale of 30 days.

[10] The experimental protocol is similar to the one described by Herbaut and Houssais [2009]. A model spin up of 23 years using the ERA40 forcing fields from 1979 to 2001 is followed by the hindcast experiment forced by the complete 44 year cycle of the reanalysis. This hindcast experiment is used to characterize the variability of the freshwater transport though the CAA and to analyze its link to the atmospheric forcing. In order to do so, linear regression analysis of various atmospheric and oceanic fields onto indices representative of this transport is used. All regressions are based on mean annual values. In support of the analysis of the hindcast experiment, a set of idealized sensitivity experiments forced by NAO-like atmospheric fields is performed. The NAO forcings are composite forcings based on the NAO index defined (unless otherwise specified) as the first principal component of the winter (NDJFM) sea level pressure (SLP) over the North Atlantic (between $20^{\circ} \mathrm{N}$ and $\left.80^{\circ} \mathrm{N}\right)$. The positive NAO (hereafter $\mathrm{NAO}^{+}$) years $(1973$, 1976, 1983, 1989, 1990, 1992, 1993, 1995, and 2000) are those for which the NAO index exceeds 1 standard deviation. The "low-frequency" part of each atmospheric composite field is obtained by first low-pass filtering the 9 year time series using a 15 day cutoff frequency and then day-by-day averaging the nine low-passed filtered annual time series. The high-frequency residual of the 9 year time series is then added to this low-frequency composite year to form 9 years of composite forcing fields. All sensitivity experiments are started from the same neutral (with regards to the NAO) ocean state obtained by running the hindcast experiment an additional 11 years period starting in 1958 until the end of 1968. Four sensitivity experiments are conducted to study the global impact of the NAO as well as the separate influence of the surface wind stress and thermodynamic flux components of the NAO forcing. In the first one (NAO), all forcing fields are $\mathrm{NAO}^{+}$composites. In the second one (WIND), the $\mathrm{NAO}^{+}$ wind stress is prescribed while the other forcing fields correspond to neutral conditions. In the third one (FLUX), the $\mathrm{NAO}^{+}$air-sea heat and freshwater fluxes are used while the other forcing fields are kept neutral. Note that the influence of the freshwater fluxes in this experiment was found to be very small so the experiment is actually exploring the sensitivity to the heat forcing. A fourth experiment (FLUX_ATL) is similar to FLUX except that the $\mathrm{NAO}^{+}$ fluxes are only applied over the part of the model domain located to the south of Davis Strait and the Greenland Scotland Ridge.

[11] In order to be able to evaluate the impact of the $\mathrm{NAO}^{+}$ atmospheric conditions, a comparison is made with results of an experiment forced by neutral NAO conditions. Neutral composite forcing fields are formed in the same way as the $\mathrm{NAO}^{+}$composites except that neutral years (1959, 1968, $1972,1981,1982,1984,1987,1988$, and 1998) are defined as those for which the NAO index is between -0.2 and 0.2 times the standard deviation. In the following, results of the $\mathrm{NAO}^{+}$ experiments are presented as anomaly fields obtained by subtracting the fields of the neutral NAO experiment from those of the $\mathrm{NAO}^{+}$experiments.

\section{Arctic Freshwater Outflow in the Hindcast Experiment}

\subsection{Mean Volume and Freshwater Transports to the North Atlantic}

[12] In this section, we discuss the mean characteristics of the transports through Fram Strait and the CAA. Unless stated otherwise, in the following the volume and freshwater transports refer to the net (outflow minus inflow) transport through the entire section of the passage with the liquid freshwater transport being calculated relative to a reference salinity of 34.8. Additionally, the term "total freshwater transport" will be used for the sum of the solid (sea ice) and liquid components of this transport. All transports are 


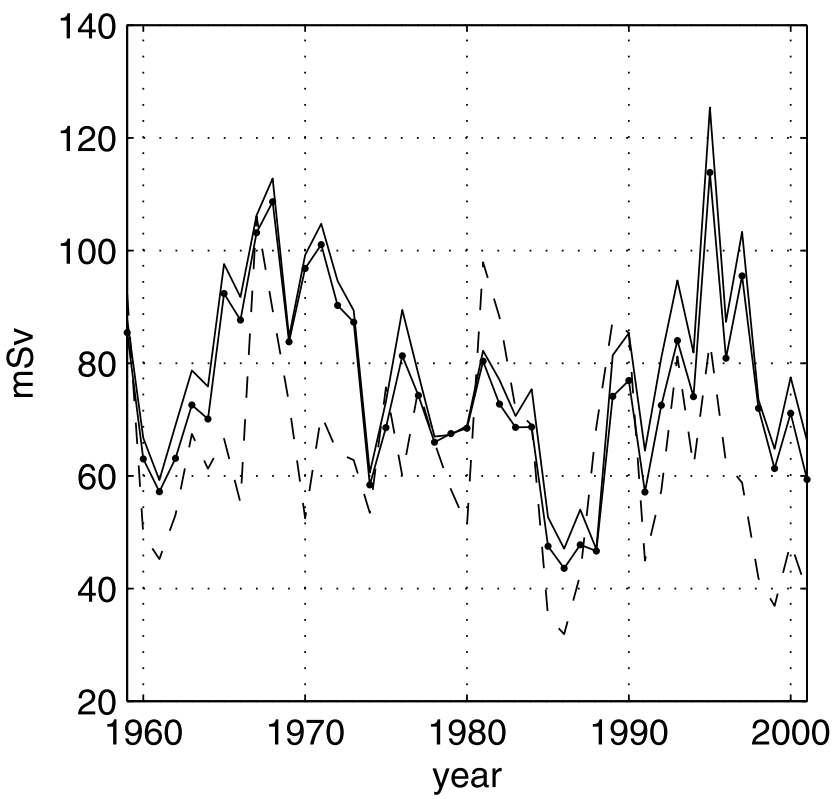

Figure 2. Mean annual (July-June) freshwater flux (mSv) through Fram Strait: solid component (dashed line), liquid component computed from the top to bottom (solid line), liquid component associated with the fresh polar water, defined as water with salinity $<34.6$ (solid line with dots).

summed up over the entire section of the passages. In the CAA, all transports are evaluated at the downstream outlet of the passages, namely Lancaster Sound (magenta dot in Figure 1) for the western passage and Smith Sound (yellow dot in Figure 1) for the eastern passage.

[13] The hindcast experiment appears realistic with regards to the volume and freshwater exchanges between the Arctic and the North Atlantic. The net volume transport through Fram Strait averages to 1.6 Sv over the period 1958-2001, being made of a northward transport of 7.4 Sv and a southward transport of $9 \mathrm{~Sv}$. This net transport is in good agreement with the estimate of $2 \mathrm{~Sv}$ calculated by Schauer et al. [2008] from 9 years of mooring observations. However, the model underestimates the individual northward and southward components of the transport when compared with the values of 12 and $14 \mathrm{~Sv}$ estimated from these observations, respectively. Still, the magnitude of the southward transport in the East Greenland Current is similar to Schlichtholz and Houssais [1999] estimate of $7 \mathrm{~Sv}$ based on an inversion of the MIZEX 84 hydrographic observations collected in summer 1984. In terms of averaged freshwater flux over the period 1958-2001, a value of $2500 \mathrm{~km}^{3} \mathrm{yr}^{-1}(79 \mathrm{mSv})$ is simulated (Figure 2). This value as well as the variability about the mean are very robust with respect to the domain over which the freshwater fluxes are cumulated, that is whether one considers the surface layer or the entire water column, the entire strait width or only the western region, all water masses or only the Polar Water ( $<<34.6$, Figure 2$)$. When the model mean annual freshwater transport is estimated based on the upper $300 \mathrm{~m}$ of the water column and averaged over the 1997-1998 2 year period, a value of $2300 \mathrm{~km}^{3} \mathrm{yr}^{-1}$ is obtained which is similar to the estimate of $2400 \pm 400 \mathrm{~km}^{3} \mathrm{yr}^{-1}$ for the upper ocean freshwater transport obtained by Serreze et al. [2006] for the same time period.
[14] The simulated mean annual ice area flux through Fram Strait is roughly $1300 \mathrm{~km}^{2} \mathrm{yr}^{-1}$ on average over the period 1978-2001, that is twice as large as the estimates of $720 \mathrm{~km}^{2} \mathrm{yr}^{-1}$ provided by Kwok [2009] based on satellite microwave observations over the same period, most probably due to too large drift velocities in the model. Still, the variability is well reproduced, with a correlation of 0.92 between the Kwok [2009] time series and the model values. Over the simulation period, the mean ice volume transport is $2010 \mathrm{~km}^{3} \mathrm{yr}^{-1}(64 \mathrm{mSv})$ and its standard deviation is $18 \mathrm{mSv}$ which both have similar magnitude as the corresponding components of the liquid freshwater export (standard deviation of $17 \mathrm{mSv}$, Figure 2). It is in agreement with the observational estimates in terms of both the mean annual value over the period 1990-1999 (2400 km $\mathrm{yr}^{3}$ [Widell et al., 2003]) and the variability over the period 19901996 (correlation of 0.65 between the simulated monthly fluxes and Vinje et al. [1998] estimates). In particular, the model reproduces the increase of the export in winter 1997 and the moderate exports in 1998 and 1999.

[15] The simulated volume transport through Lancaster Sound is in relatively good agreement with observations. From August 1998 to August 2004, moorings placed across Lancaster Sound revealed an increasing transport there, from a value of $0.40 \mathrm{~Sv}$ in 1998 to values of 0.90 and $0.95 \mathrm{~Sv}$ in 1999 and 2000, respectively [Melling et al., 2008]. The volume transport in the model shows a similar increase of the transport from 1.05 Sv in 1998 to $1.30 \mathrm{~Sv}$ in 1999 and $1.35 \mathrm{~Sv}$ in 2000 . These values take into account all the water flowing through Amundsen Bay and McClure Strait but also water which in reality flows through Cardigan Strait and Hell Gate to Jones Sound. Adding the transports of 0.2 and $0.1 \mathrm{~Sv}$ observed in Cardigan Strait and Hell Gate over the period 1998-2002 [Melling et al., 2008] to the transport measured in Lancaster Sound leads to a total volume transport close to the simulated values in Lancaster Sound. In Nares Strait, the mean volume transport simulated over the period 19582001 is $1.3 \mathrm{~Sv}$ (with a standard deviation of $0.2 \mathrm{~Sv}$ ) and largely exceeds the recent observational estimate of $0.6 \pm$ 0.1 Sv calculated by Münchow and Melling [2008] for the period 2003-2006. While the model consequently overestimates the transport through the CAA, the simulated and observed mean volume transports at Davis Strait [Cuny et al., 2005] are of similar magnitude (2.9 and $2.6 \pm 1.0 \mathrm{~Sv}$, respectively) over the period September 1987 to August 1990. The large uncertainty on the observed transport, however, may be responsible for the apparent inconsistency between the mean observed transports through the CAA and Davis Strait, and suggests that a reliable validation of the simulated transports would require longer observational time series to average out the interannual variability.

[16] The volume transports simulated in the CAA are associated with too large liquid freshwater export compared with the observations. The mean value of $135 \mathrm{mSv}$ simulated over the period 1998-2001 is indeed larger than the value of $101 \pm 10 \mathrm{mSv}$ proposed by Serreze et al. [2006] based on a time series extrapolated from Prinsenberg and Hamilton [2005] data using numerical simulation results. The discrepancy between the simulated and observed transports is partly due to the polar water being too fresh in the model. Consistently with this explanation, in Davis Strait, the simulated freshwater transport $(170 \mathrm{mSv})$ over the period 

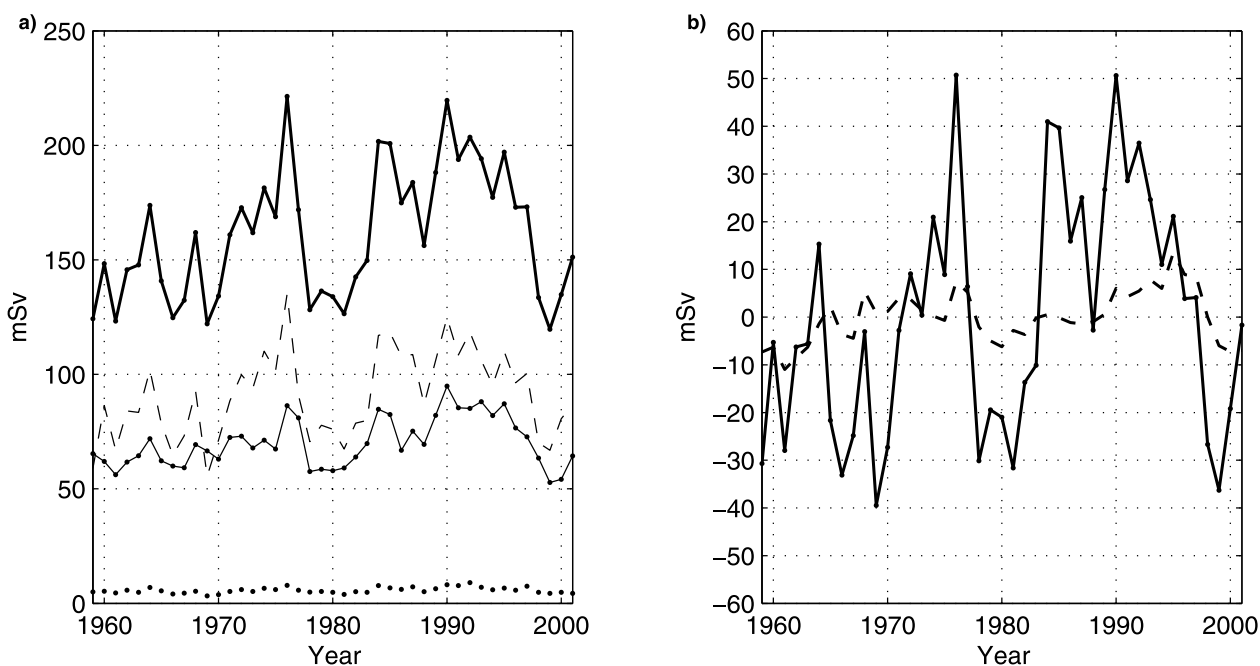

Figure 3. Mean annual (July-June) (a) total (sea ice and liquid water) freshwater flux (mSv) through the CAA (bold solid line) and the contributions to this flux from Lancaster Sound (dashed line), Smith Sound (solid line with dots) and sea ice in both passages (dotted line) and (b) contributions $\frac{-\boldsymbol{U}^{\prime}\left(\overline{\boldsymbol{S}}-\boldsymbol{S}_{\text {ref }}\right)}{\boldsymbol{S}_{\text {ref }}}$ (solid line) and $\frac{-\bar{U} S^{\prime}}{S_{r e f}}$ (dashed line) to the liquid freshwater flux through the CAA.

September 1987 to August 1990 is greater than the value of $92 \pm 34 \mathrm{mSv}$ estimated by Cuny et al. [2005] from current meter moorings over the same period although the simulated and observed water volume transports are of similar amplitude. The discrepancy between the simulated and observed freshwater transports may even be larger as the current meter array was missing part of the northward flow of relatively freshwater on the Greenland shelf, likely leading to a bias toward high values of the freshwater export [Tang et al., 2004].

\subsection{Variability of the Freshwater Transport Through the CAA}

[17] The variability of the simulated mean annual ice export through the CAA in the hindcast experiment amounts to less than $5 \%$ of that of the liquid freshwater transport. The latter displays strong variability at low frequency (Figure 3a) with large exports in the mid-1970s, the mid-1980s, and the early $1990 \mathrm{~s}$. To determine the origin of this variability, the contributions of the anomalous advection of the mean salinity, $\frac{-\boldsymbol{U}^{\prime}\left(\overline{\boldsymbol{S}}-\boldsymbol{S}_{\text {ref }}\right)}{\boldsymbol{S}_{\text {ref }}}$, of the mean advection of salinity anomalies by the mean current, $\frac{-\bar{U} S^{\prime}}{S_{\text {ref }}}$, and of the anomalous advection of salinity anomalies, $\frac{-U^{\prime} S^{\prime}}{S_{r e f}}$, have been computed separately. The latter contribution is found to be negligible. The standard deviation of the contribution $\frac{-\boldsymbol{U}^{\prime}\left(\overline{\boldsymbol{S}}-\boldsymbol{S}_{\text {ref }}\right)}{\boldsymbol{S}_{\text {ref }}}$ is more than 4 times greater than that of the contribution $\frac{-\bar{U} \boldsymbol{S}^{\prime}}{\boldsymbol{S}_{\text {ref }}}$ (Figure $3 \mathrm{~b}$ ), showing that the variability of the freshwater transport is mainly driven by the water volume transport. The latter contribution indeed explains $99 \%$ of the variance of the liquid freshwater transport while the advection of salinity anomalies only explains $46 \%$. It is therefore conceivable to try to explain this variability by identifying mechanisms driving the water volume transport through the different passages.

[18] The volume transports through the two channels connecting the Arctic Ocean to Baffin Bay in the model have been diagnosed separately at Lancaster Sound and Smith Sound. They display similar variances and are well correlated (0.7) at 0 lag, suggesting a similar source of variability. All individual transports as well as their total indeed show a strong correlation with the SSH difference between the upstream (on the Arctic side) and the downstream (on Baffin Bay side) ends of the channels (Figures $4 \mathrm{a}$ and $4 \mathrm{~b}$ ). The impact of the along-strait SSH gradient, estimated from this $\mathrm{SSH}$ difference, is however stronger in Nares Strait as shown by the very high correlation (0.9) found there (Figure 4b). Comparatively, the along strait SSH difference in the western channel shows a comparatively weak correlation of 0.53 with the outflow to Lancaster Sound. The latter indeed correlates higher with the cross-strait $\mathrm{SSH}$ gradient at the entrance of McClure Strait (Figure 4a), suggesting that the regional geostrophic flow there controls, at least partly, the variability of the inflow to the channel. The contrast between the eastern and western channels of the CAA also applies for the relative influence of the upstream and downstream SSH forcing on the transports, as shown by the different levels of correlation (Figures $4 \mathrm{a}$ and $4 \mathrm{~b}$ ). In the western channel, the correlations of the transport with the $\mathrm{SSH}$ at the entrance of McClure Strait and the SSH downstream of Lancaster Sound are not significant at any lag (Figure 4a). Note that here and in the following, a 95\% level of confidence is used to decide on the significance of the correlations. By contrast, a strong response of the water transport to the downstream SSH variability in Baffin Bay is found in Nares Strait where the correlation of the transport with the SSH in Smith Sound reaches -0.7 (Figure $4 b$ ).

\subsection{Arctic Forcing on the CAA Outflow}

[19] Among the different passages contributing to the volume outflow to Lancaster Sound, the inflow to McClure Strait does not provide the main contribution in terms of mean annual transport over the simulation period but its variability dominates, contributing to approximately $65 \%$ of the 

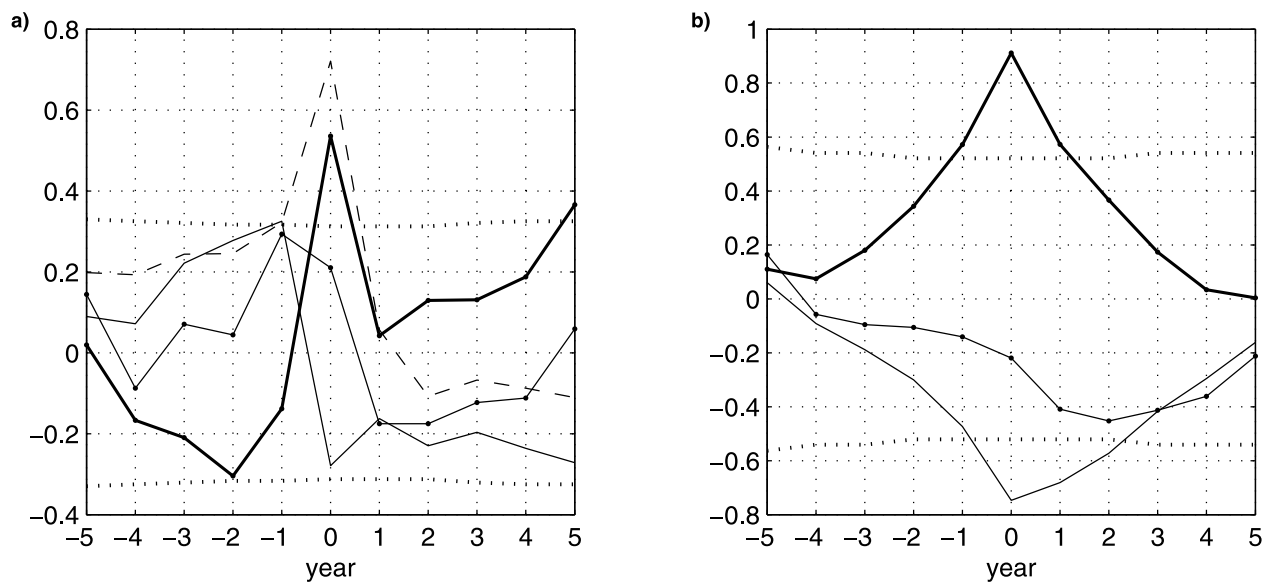

Figure 4. Correlation of the mean annual volume transport in (a) Lancaster Sound and (b) Smith Sound with the mean annual upstream (solid line with dots) and downstream (solid line) sea surface heights and their difference (bold solid line). Also shown in Figure 4a as a dashed line is the correlation of the transport in Lancaster Sound with the cross-strait gradient north of McClure Strait. The dotted lines indicate the 95\% level of significance. See the blue boxes in Figure 1 for the locations where SSHs are calculated.

standard deviation of the outflow (Figure 5). A section of the along-channel velocity at the entrance of the strait regressed onto the volume outflow to Lancaster Sound (Figure 6a) shows velocity anomalies mainly distributed over the upper $250 \mathrm{~m}$. The anomalies have a subsurface maximum at about $90 \mathrm{~m}$, well below the Ekman layer, which expresses the intensification of the flow against the southern boundary of the strait.

[20] In order to understand the link between the variability of the inflow to McClure Strait and the circulation upstream in the Arctic, an index of the variability of this inflow has been constructed which was set equal to the annual average of the along-strait velocity anomaly in the core of the anomaly shown in Figure 6a. Regression of the surface Ekman velocity onto this index (Figure 7) suggests that the variability of the surface circulation in the strait is not directly connected to anomalies of the Ekman surface flow. The latter mainly tends to export water from the Beaufort Gyre region toward the southern and eastern Beaufort Sea but very marginally into the strait. The calculated contribution of the local Ekman transport to the transport anomaly in the strait is indeed negligible. By contrast, the regression of the annual ocean velocities at $90 \mathrm{~m}$ on the McClure Strait velocity index (Figure $8 \mathrm{~b}$ ) shows large areas of significance in the Arctic Ocean at the periphery of the Canada Basin, with a circulation pattern suggesting a link between the strength of the subsurface gyre circulation in the Canada Basin and the outflow to McClure Strait. A slope current anomaly, characterized by a core sitting above the upper continental slope, is indeed identified all around the basin, from the southern Beaufort Sea (Figure $6 b$ ) to the north of the archipelago. The velocity anomalies above the shelf are comparatively small. The subsurface velocity anomalies are organized as an anticlockwise current with a part entering McClure Strait and providing most of the variability of the transport there. Superimposed on the mean anticyclonic gyre circulation of the Canada Basin (Figure 8a), this anomalous transport tends altogether to slow down the gyre circulation and to promote diversion of a branch of this circulation into McClure Strait. It should be noted that another branch is also diverted toward the Amundsen Bay but in fact recirculates westward and northward to finally enter McClure Strait.

[21] The large-scale anticlockwise circulation anomaly has a strong signature in the SSH distribution as shown by the simultaneous regression of the mean annual SSH onto the McClure velocity index (Figure 9a). Associated with enhanced outflows to McClure, a SSH drop is found in the central Canada Basin while a band of SSH anomalies of opposite sign appears at the periphery of the basin, above the continental shelf. The two features are concomitant which is consistent with them having a common origin in the anomalous surface Ekman flow shown in Figure 7. A more divergent Ekman flow in the basin altogether flushes more surface waters from the basin interior to its periphery, leading to water accumulation over the shelf, and generates vertical pumping velocities in the water column which impact the

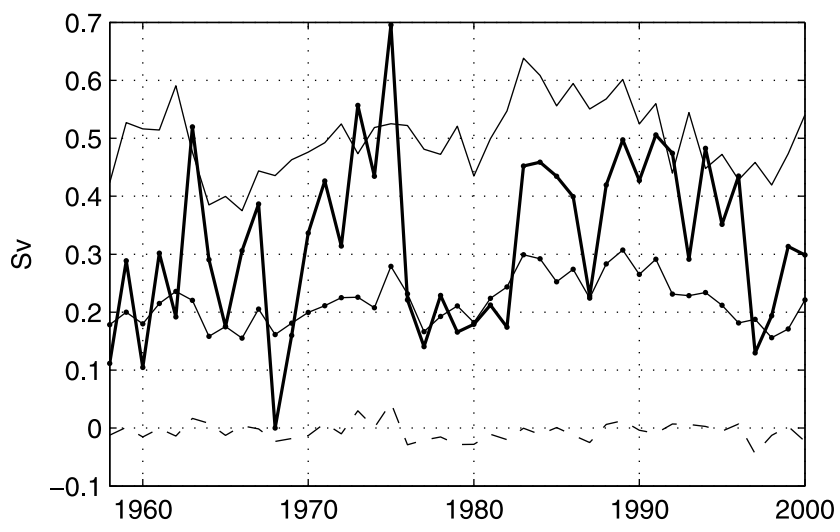

Figure 5. Mean annual volume transport (Sv) through McClure Strait (bold solid line), Amundsen Gulf (dashed line), Byam Martin Strait (solid line), and Penny Channel (solid line with dots). 

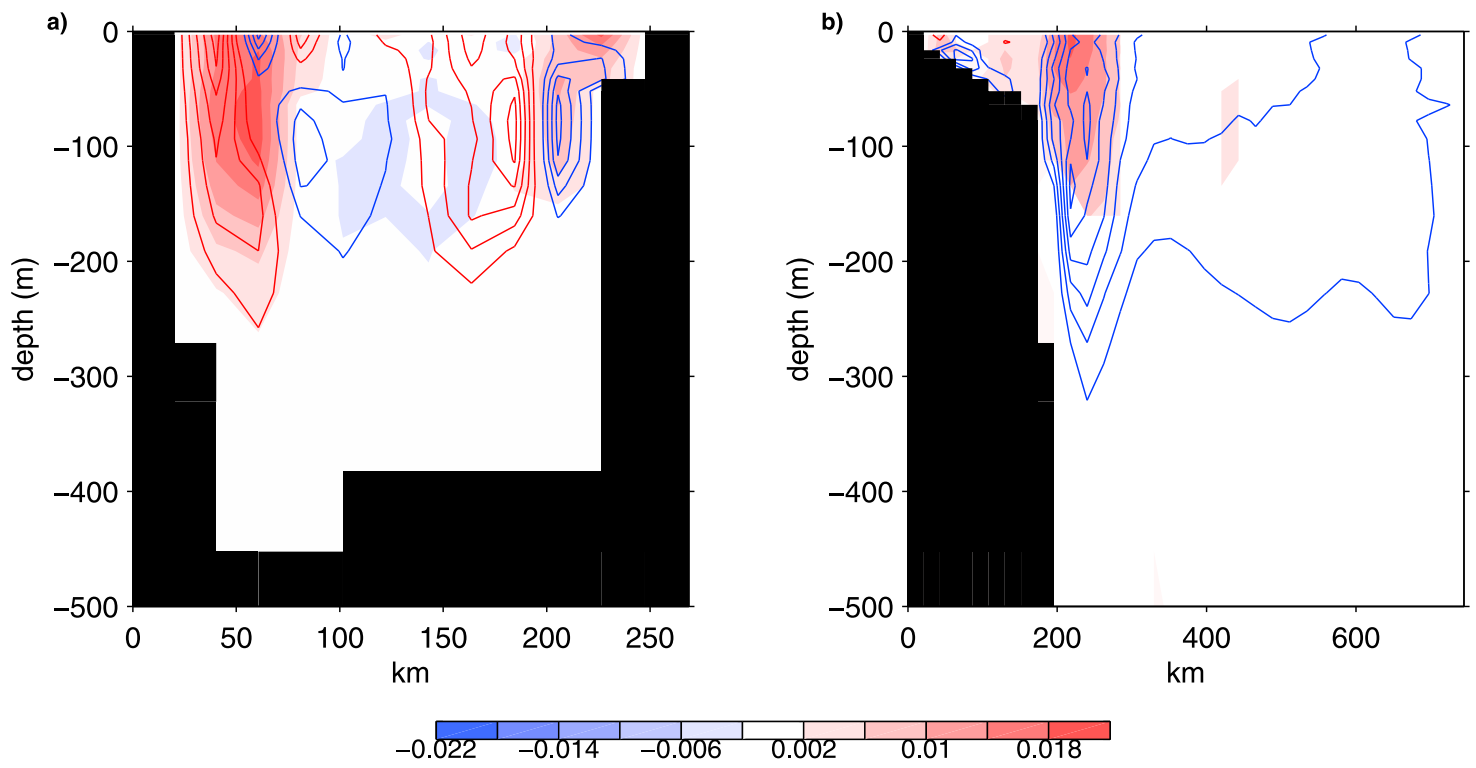

Figure 6. Normal (along-strait) velocity on a section across (a) McClure Strait and (b) the southern Beaufort Sea shelf-slope region (see Figure 1 for the location of the sections). Shown on each section are the averaged flow (line contours with increment $0.6 \mathrm{~cm} \mathrm{~s}^{-1}$ ) and the simultaneous regression of the annual velocity anomalies $\left(\mathrm{m} \mathrm{s}^{-1}\right.$ ) onto the annual outflow to Lancaster (shaded contours), both estimated over the 1958-2001 period. Red (blue) contours indicate flow from (to) the Arctic Ocean. Regression is shown for enhanced outflow to Lancaster Sound. Only the values significant at the $95 \%$ level are shown.

large-scale gyre circulation of the Canada Basin. The maximum divergence of the Ekman flow associated with the flow variability in McClure Strait, as identified by the center of action of the wind stress curl anomaly (Figure 10a), is located to the northeast of the Chukchi Plateau and therefore coincides with the center of the Beaufort Gyre (Figure 11). The associated SSH response (Figure 9a) however shows a different pattern compared with the wind stress curl, suggesting that the response of the gyre circulation to Ekman pumping variations is more complex than a simple modulation of the gyre intensity.

[22] What actually controls the diversion of the current into McClure Strait is a local distortion of the large-scale gyre circulation which occurs north of the Archipelago and is clearly identified in the composites of the SSH associated with the velocity index in McClure Strait (Figure 11). During years of enhanced inflow to the strait (Figure 11a), in addition to a weakening of the gyre circulation, the composite SSH gradient immediately upstream of McClure Strait shows a southwest-northeast orientation conducive to a flow into the strait. By contrast, during years of reduced inflow and intensified gyre circulation (Figure 11b), the SSH distribution north of the strait shows a weaker cross-strait gradient favoring enhanced recirculation around the Canada Basin. We postulate that this rearrangement of the $\mathrm{SSH}$ gradient west of McClure Strait is the process responsible for modulating the amount of water brought onto the shelf and into the strait.

[23] The SSH regression onto the McClure velocity index shows insignificant values over the shelf to the northeast of the strait but significant ones to the southwest (Figure 9a). The variability of the cross-strait SSH gradient at the entrance of the strait therefore appears to be dominated by the SSH variability to the south of the strait. The correlation of the

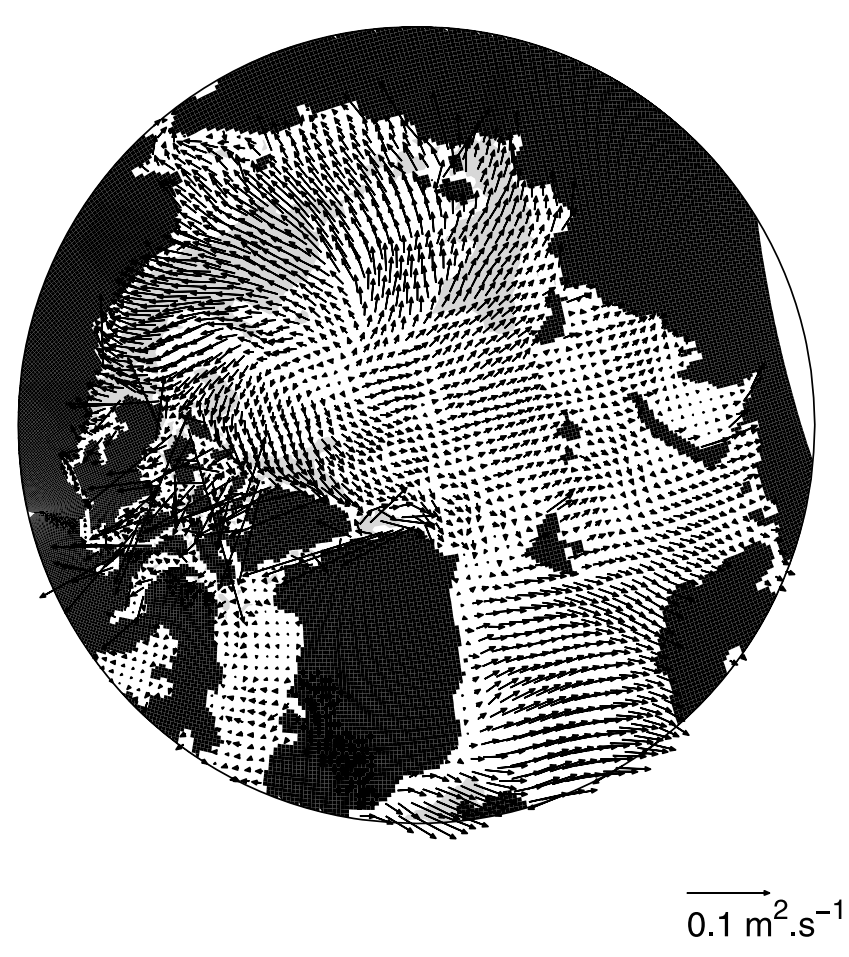

Figure 7. Simultaneous regression of the annual Ekman transport on the velocity index (see definition of the index in text) in McClure Strait. The regression is calculated over the 1958-2001 period. The gray-shaded areas indicate the $95 \%$ level of significance. 

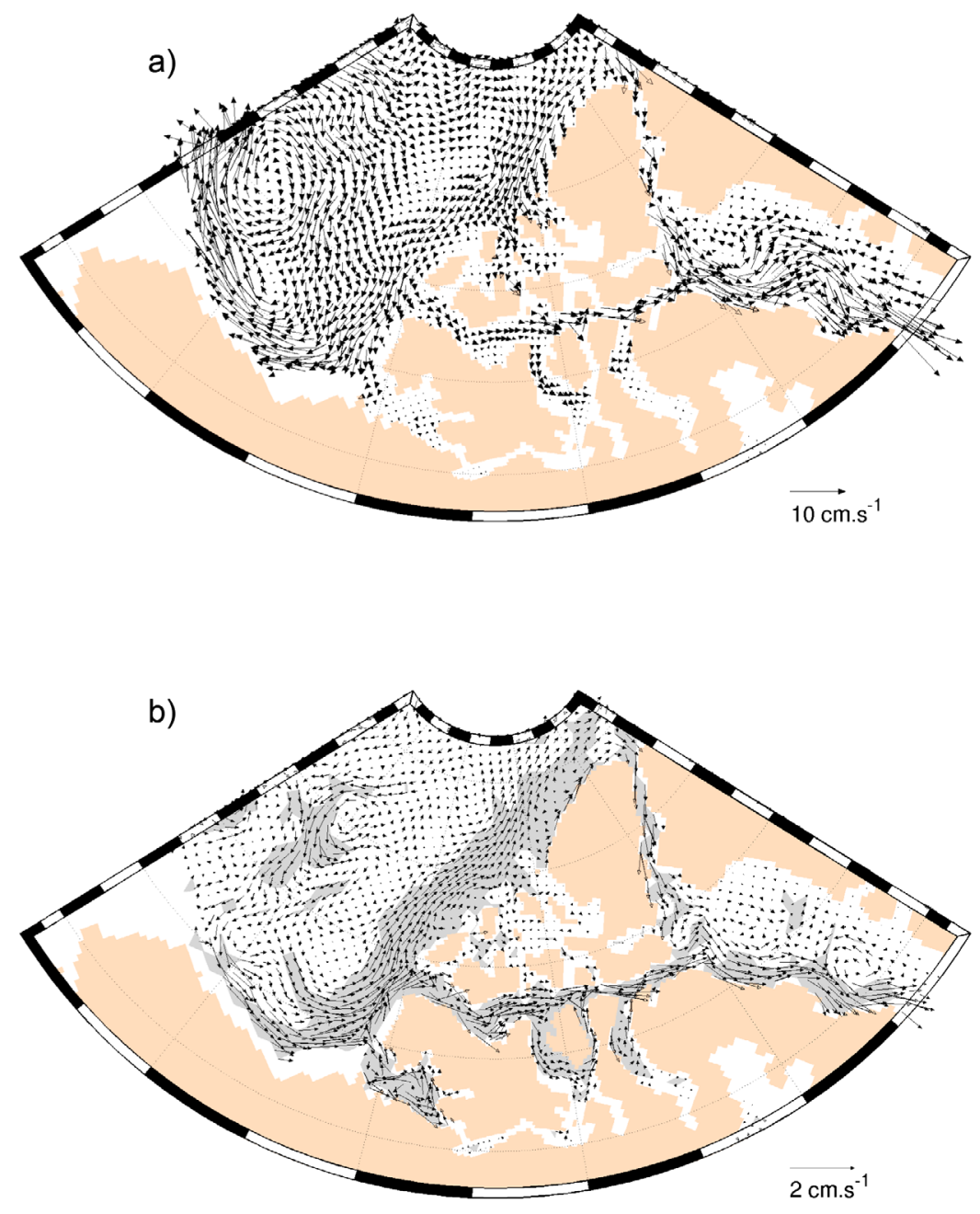

Figure 8. Mean annual velocity at $90 \mathrm{~m}$ : (a) 1958-2001 average and (b) simultaneous regression of the anomalies on the velocity index in McClure Strait (see definition of the index in text) over the 19582001 period. Regression is shown for enhanced inflow to McClure Strait. The bold black contour indicates the $95 \%$ level of significance.

latter with the McClure velocity index is 0.63 . By contrast, the correlation of this index with the $\mathrm{SSH}$ in the center of the Beaufort Gyre is insignificant $(\mathrm{r}=-0.17)$.

\subsection{Subpolar Forcing on the CAA Outflow}

[24] In contrast with the flow to Lancaster Sound which shows a strong link to the upstream SSH distribution in the Arctic, that in Nares Strait is more strongly linked to the SSH variability downstream in Smith Sound (Figure 4b). The latter appears to be connected to the variability of the SSH in the western North Atlantic subpolar gyre, both simultaneously (Figure 9b) and when the latter leads the SSH in Smith Sound by a year. These subpolar SSH anomalies are associated with atmospheric heat flux anomalies generated in the Labrador Sea (Figure 12). The SSH response in Baffin Bay is a lagged response as demonstrated by the larger heat flux anomalies found a year before the SSH anomalies (Figure 12a) compared to the simultaneous response (Figure 12b). By contrast, there is little connection between wind stress curl anomalies in the western subpolar gyre and the SSH in Smith Sound (Figure 10b), and the small pattern of significant wind stress curl anomalies in southern Baffin Bay would in fact tend to create $\mathrm{SSH}$ anomalies of opposite sign compared to the local SSH in Smith Sound.

[25] Although the eastern and western passages respond to distinct components of the atmospheric surface forcing (wind stress in the Arctic and air-sea heat flux in the subpolar gyre, respectively), as mentioned earlier, a high correlation is found between the transports in the two passages (Figure 3a). We hypothesized that this is due to the fact that the two passages correlate with components of the atmospheric forcing which are both linked to the same large-scale atmospheric variability. At lag 0, the regression of the winter (NDJFM) SLP on the annual mean volume transport through the CAA displays a dipole pattern, with a pole centered over the Arctic and extending southward over Greenland and into the eastern Baffin Bay, and another pole of opposite sign centered over the northern North Atlantic (Figure 13). Similar patterns (not shown) are found when the regressions are done separately on the eastern or western channel, confirming that the surface atmosphere generates a coherent response of the different passages of the CAA. In section 4, we show that this response 
a)

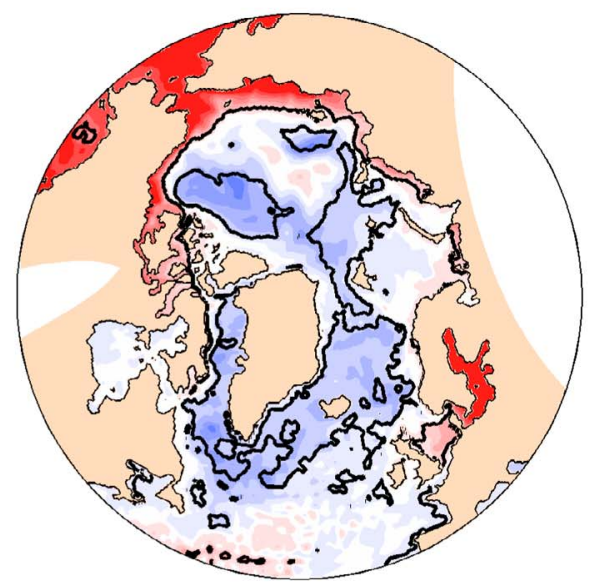

b)

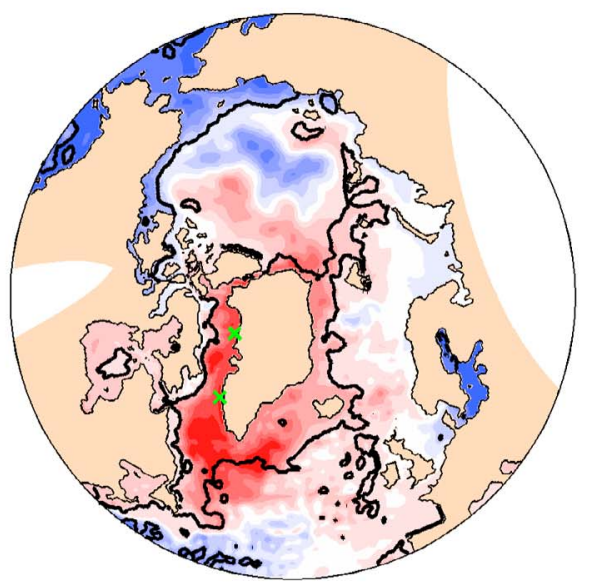

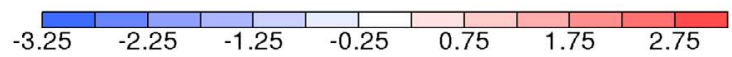

Figure 9. Simultaneous regression $\left(10^{-2} \mathrm{~m}\right)$ of the annual sea surface height on (a) the velocity index in McClure Strait and (b) the annual SSH in Smith Sound. Also shown in Figure 9b as green crosses are the locations where northward propagation of SSH anomalies has been diagnosed (see section 4). Regressions are estimated over the 1958-2001 period and in Figure 9a a positive index indicates enhanced outflow to Baffin Bay. See the blue boxes in Figure 1 for the exact location where the SSH in Smith Sound is calculated. The bold black contour indicates the $95 \%$ level of significance.

is primarily driven by anomalies of the atmospheric surface forcing related to the NAO.

\section{Atmospheric Forcing and the CAA Outflow: The Particular Role of the NAO}

[26] The SLP pattern in Figure 13 resembles the winter NAO or AO patterns defined in the literature [Thompson and Wallace, 2000; Hurrell and van Loon, 1997]. In order to confirm the link between the NAO and the volume transports through the CAA, the latter has been correlated with the winter NAO index (see section 2 for the calculation of this index). The correlation of the NAO with the transport through Nares Strait is maximum (with a peak value of 0.55 ) when the NAO leads the transport by 1 year, whereas, for the transport in Lancaster Sound the maximum correlation is lower $(0.30)$ and occurs in phase. Moreover, the correlation with Nares Strait is robust while, for the Lancaster transport, it is very
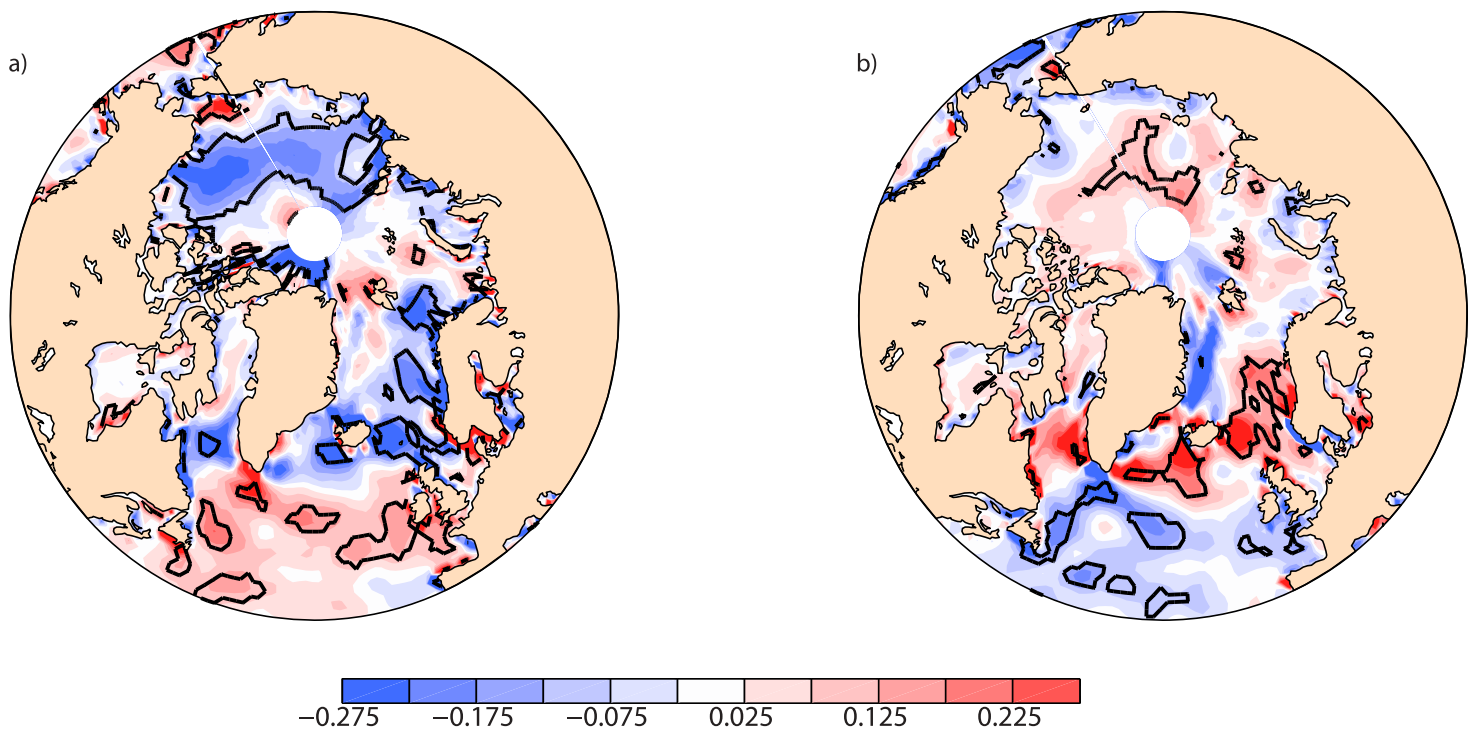

Figure 10. Same as (a) Figure 9a and (b) Figure 9b except for simultaneous regression of the mean annual wind stress curl $\left(10^{-7} \mathrm{~N} \mathrm{~m}^{-3}\right)$. 

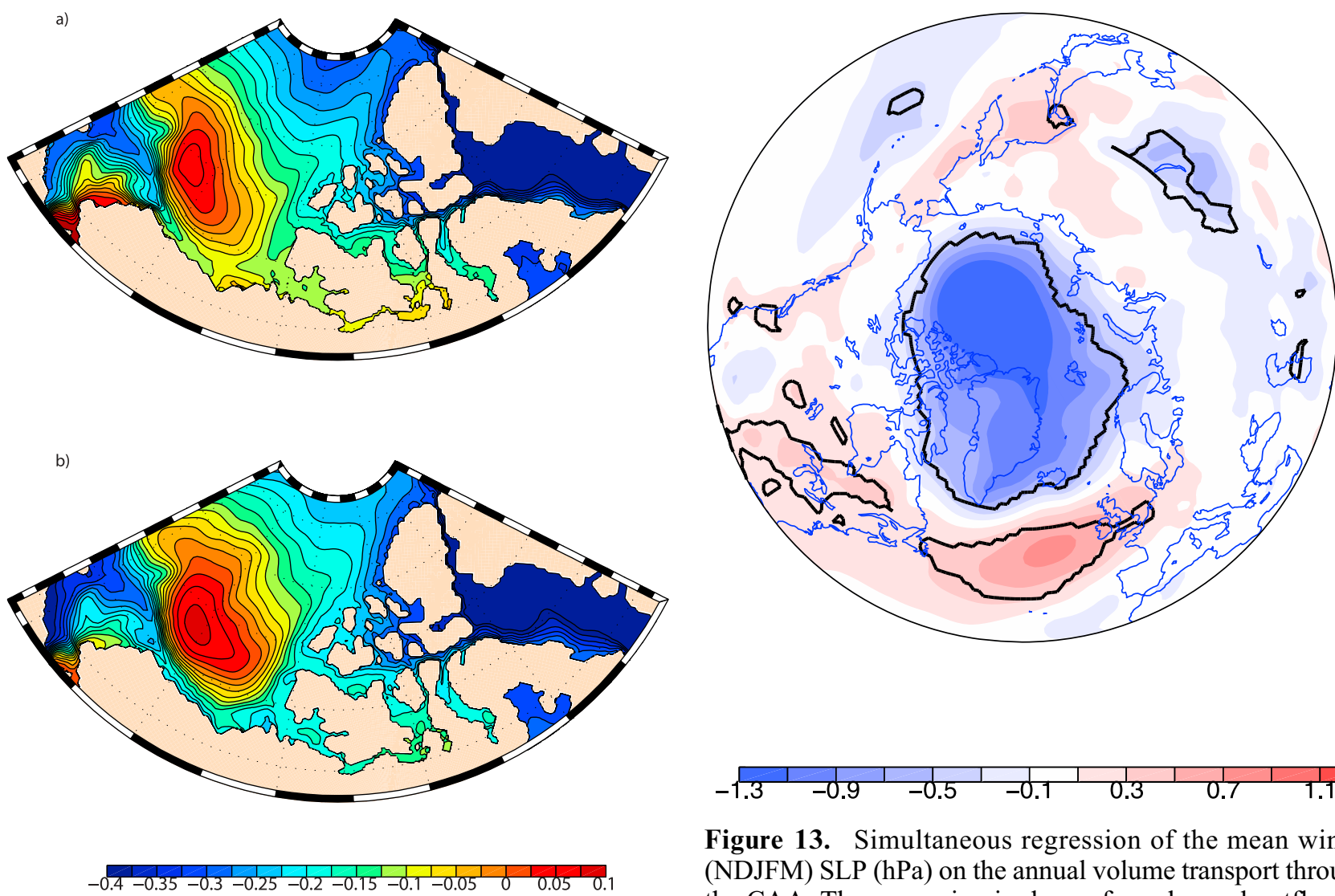

Figure 11. Composites of the SSH (m) based on the velocity index in McClure Strait: (a) when the index shows a flow toward Baffin Bay and (b) when the index shows a flow toward the Arctic Ocean. Composite years are those for which the modulus of the velocity anomaly exceeds 1 standard deviation of the 44 year time series.

a)

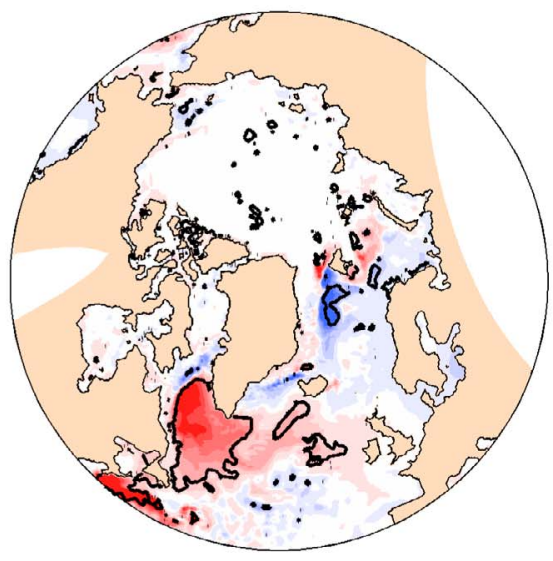

b)

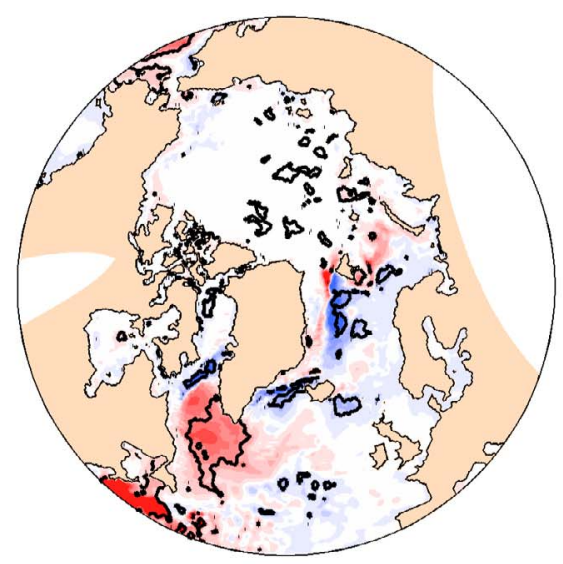

Figure 13. Simultaneous regression of the mean winter (NDJFM) SLP ( $\mathrm{hPa}$ ) on the annual volume transport through the CAA. The regression is shown for enhanced outflow to Baffin Bay. The bold black contour indicates the $95 \%$ level of significance.

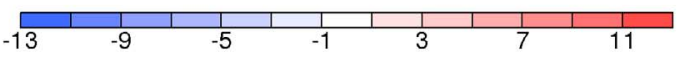

Figure 12. The (a) 1 year lagged (heat flux leads) and (b) simultaneous regressions of the mean annual surface heat flux $\left(\mathrm{W} \mathrm{m}^{-2}\right)$ on the annual SSH in Smith Sound. The bold black contour indicates the $95 \%$ level of significance. 
a)

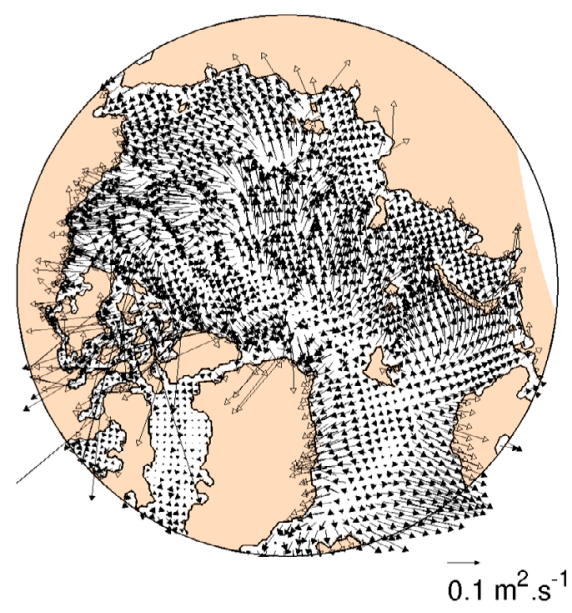

b)

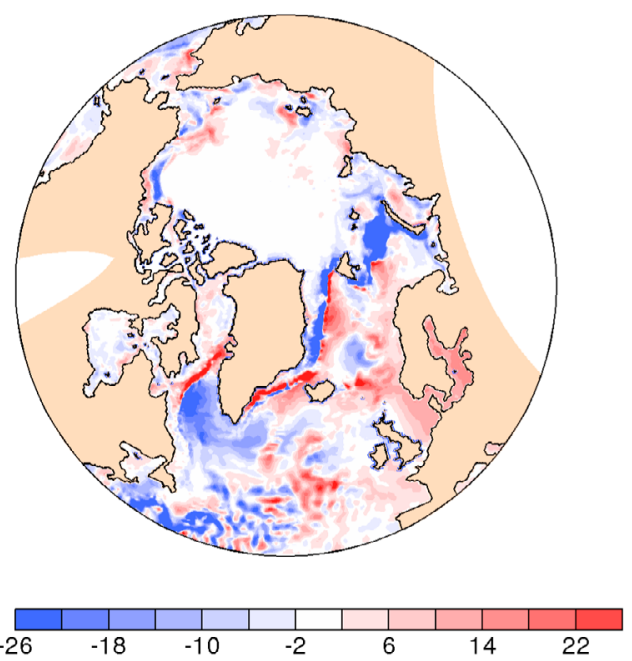

Figure 14. (a) Ekman transport anomaly and (b) surface heat flux anomaly $\left(\mathrm{W} \mathrm{m}^{-2}\right)$ obtained by substracting fields of the experiment with neutral NAO forcing from the experiment NAO. Positive values of the heat flux indicate a heat gain for the ocean.

sensitive to the definition of the NAO index, especially the domain and time period selected for the empirical orthogonal function (EOF) analysis. When the EOF analysis of the NDJFM SLP is extended to the entire Northern Hemisphere (north of $20^{\circ} \mathrm{N}$ ) including the Arctic Ocean to obtain the AO index, the correlation of the mean annual transport at Lancaster with the AO index increases to 0.39 . When mean winter values restricted to the DJF period are used for both the transport and the NAO, the correlation between the transport and the NAO index increases to 0.44 , and to 0.57 if the AO is used instead of the NAO. The transport in Lancaster Sound therefore appears to be more sensitive to the conditions in the Arctic Ocean than that through Nares Strait.

[27] Since the NAO appears as a major forcing for the volume transport in the CAA, the model has been used to perform sensitivity experiments forced by NAO-like surface atmospheric forcing fields (experiment NAO, see section 2 for the design of these experiments). In order to further investigate how the different components of the atmospheric forcing act on the outflow, specific experiments have been run which allow us to separate the respective influence of the wind stress and heat fluxes (experiments WIND and FLUX), or to highlight the impact of remote versus local heat fluxes (experiment FLUX_ATL). The Ekman transport and surface heat flux anomalies (Figures 14a and 14b) associated with the wind stress and thermodynamic forcings in the WIND and FLUX experiments, respectively, are obtained by subtracting the corresponding neutral NAO composite field from the positive NAO composite. They compare very well with the regression patterns on the CAA outflow shown in Figures 7 and 12, confirming that these sensitivity experiments are appropriate to analyze the mechanisms driving this outflow.

[28] Experiment NAO shows that a positive NAO can drive a $20-25 \%$ increase of the transport (averaging to about $0.5 \mathrm{~Sv}$ over the 10 years of the experiment) through the CAA
(Figure 15a). Additionally, the response of the transport is linear with respect to the forcings in the first 4 years of the simulation (i.e., the transport in experiment NAO is equal to the sum of the transports in experiments WIND and FLUX) while, later on, nonlinearities tend to reduce the cumulative effect of the wind stress and the heat fluxes. In experiment WIND, the volume transport anomaly displays a peak at $0.4 \mathrm{~Sv}$ after 3 years of integration and then decreases afterward (Figure 15a) so that the average transport anomaly in the last 4 years of the experiment is only $0.28 \mathrm{~Sv}$ (Table 1 ). The transport increase in Lancaster Sound at that time is almost twice as much as that in Nares Strait (Figure 15b and Table 1). Judging from Figure 15b, the wind stress is indeed the major forcing of the transport in Lancaster Sound while, in Nares Strait, the response to the heat flux dominates after 4 years of integration. The SSH anomalies in WIND (Figure 16a) also show some resemblance with the SSH regression pattern associated with enhanced outflow to McClure Strait in the hindcast experiment (Figure 9a). In both cases, the SSH distribution is characterized by noticeable negative anomalies in the central part of the Canada Basin surrounded by positive anomalies in the southern and eastern Beaufort Sea. In the Makarov and Amundsen basins, the response is however much weaker in the hindcast experiment, showing even areas of opposite sign anomalies, which suggests other mechanisms than a purely wind driven response to the NAO there. Still, these similarities provide evidence that wind driven variations of the Beaufort Gyre circulation indeed control part of the variability of the water export through the CAA. By contrast, the SSH anomalies generated in Baffin Bay and the Labrador Sea in the WIND experiment are very small (Figure 16a), suggesting that the wind-driven variability has little impact on the SSH response there.

[29] In experiment FLUX, the transport through the CAA displays a different evolution compared with WIND. It is marked by a regular increase till a maximum is reached after 

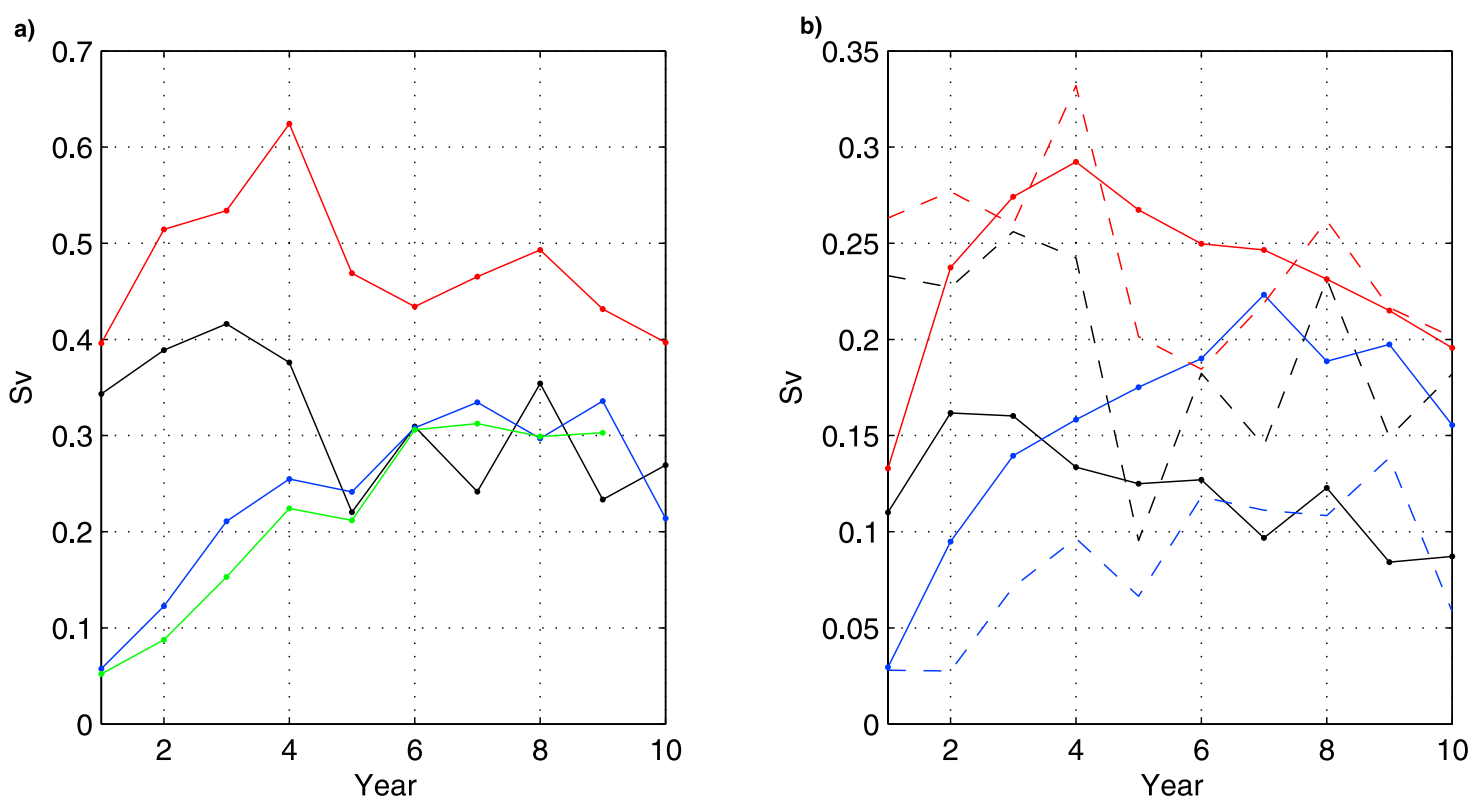

Figure 15. Mean annual volume transport anomaly (Sv) through (a) the CAA and (b) Lancaster Sound (dashed line) and Smith Sound (solid line with dots) in experiments WIND (black), FLUX (blue), NAO (red), and, in Figure 15a, FLUX_ATL (green).

5-7 years of integration (Figure 15a). The resulting transport anomaly averaged over the last 4 years of the experiment $(0.3 \mathrm{~Sv})$ is equivalent to that simulated in WIND (Table 1). The distribution between Lancaster Sound and Smith Sound is however different compared with WIND with a transport twice as large in Smith Sound (Figure 15b and Table 1) during that period. In contrast to WIND, the SSH anomalies in FLUX are small in the Arctic whereas a pattern of strong negative anomalies forms in the Labrador Sea and in eastern Baffin Bay (Figure 16b). This negative pattern resembles the pattern of SSH variability associated with the SSH variations in Smith Sound in the hindcast experiment (Figure 9b). In experiment FLUX_ATL where the same large ocean surface heat loss is applied in the Labrador Sea as in FLUX (Figure 14b) a similar drop of the SSH is observed there. More importantly, even though no forcing anomaly is applied in Baffin Bay in experiment FLUX_ATL, a similar SSH drop is observed in the bay in the two experiments (Figure 16c) which also simulate very similar volume transports in the CAA (Figure 15a and Table 1). All these results provide evidence that part of the variability of the CAA outflow can be forced by the large surface heat loss anomaly in the Labrador Sea associated with the NAO. The resulting ocean surface cooling is responsible for a decrease of the SSH in the Labrador Sea which tends to propagate northward along the western Greenland slope into Baffin Bay.
[30] The different time evolutions of the response of the CAA outflow in experiments WIND and FLUX are consistent with the different correlations between the transports through the individual channels and the NAO in the hindcast experiment. In particular, the maximum correlation obtained for the transport through Nares Strait at a 1 year lag contrasts with the maximum correlation at 0 year lag for Lancaster Sound. Whereas in the WIND experiment the transports in the CAA quickly (within a year) adjust to the forcing, in the FLUX experiment the stronger response in the Nares Strait is obtained through a gradual increase in about 5 years. Therefore, the 1 year time lag can be interpreted as the time for the stratification in the Labrador Sea to adjust to the surface heat forcing and to build corresponding anomalies in the SSH distribution there which are subsequently propagated northward.

[31] The proposed scenario also explains the stronger response to the NAO in Nares Strait as compared to Lancaster Sound when the model is forced by air-sea heat fluxes. Time series based on high-frequency (5 day averages) SSH variations in the FLUX experiment calculated at two locations along the western slope of Greenland, one in the Labrador Sea and the other one in Baffin Bay (see green crosses in Figure 9b) indeed show very similar variability. Moreover, the highest correlation of approximately 0.7 between the two time series is obtained at lags of a few days, which suggests

Table 1. Mean Annual Volume Transport (Sv) Anomaly, With Regard to Experiment With Neutral NAO Forcing, Through Each of the Two Channels of the Canadian Arctic Archipelago as Simulated in the Four Sensitivity Experiments to NAO-Like Atmospheric Forcing

\begin{tabular}{|c|c|c|c|c|c|c|c|c|}
\hline & \multicolumn{2}{|c|}{ Experiment WIND } & \multicolumn{2}{|c|}{ Experiment FLUX } & \multicolumn{2}{|c|}{ Experiment FLUX_ATL } & \multicolumn{2}{|c|}{ Experiment NAO } \\
\hline & $\begin{array}{c}\text { Average } \\
\text { Years 1-4 }\end{array}$ & $\begin{array}{c}\text { Average } \\
\text { Years } 7-10\end{array}$ & $\begin{array}{c}\text { Average } \\
\text { Years 1-4 }\end{array}$ & $\begin{array}{c}\text { Average } \\
\text { Years 7-10 }\end{array}$ & $\begin{array}{c}\text { Average } \\
\text { Years 1-4 }\end{array}$ & $\begin{array}{c}\text { Average } \\
\text { Years 7-9 }\end{array}$ & $\begin{array}{c}\text { Average } \\
\text { Years 1-4 }\end{array}$ & $\begin{array}{c}\text { Average } \\
\text { Years } 7-10\end{array}$ \\
\hline Nares Strait & 0.14 & 0.10 & 0.11 & 0.19 & 0.10 & 0.19 & 0.23 & 0.22 \\
\hline Lancaster Sound & 0.24 & 0.18 & 0.06 & 0.10 & 0.02 & 0.11 & 0.28 & 0.22 \\
\hline
\end{tabular}


a)

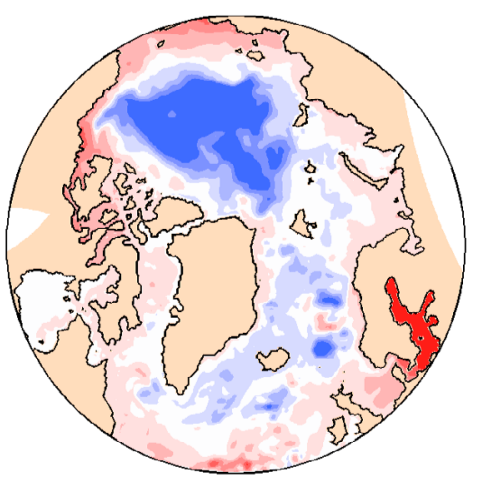

b)

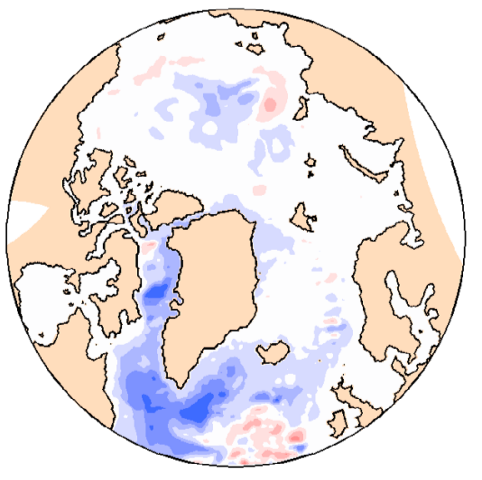

c)
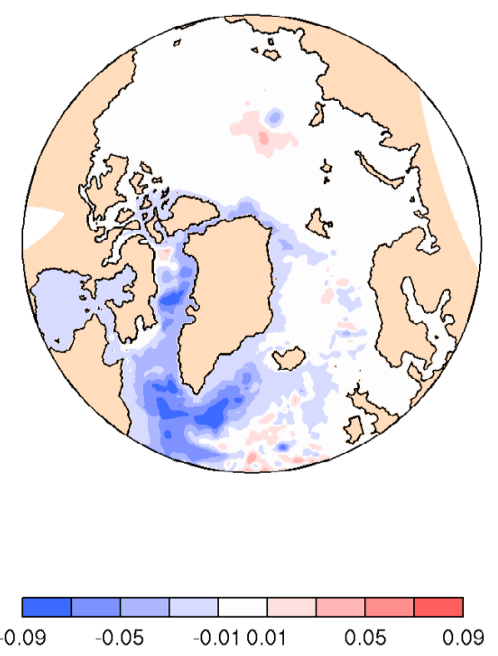

Figure 16. SSH anomaly (m) averaged over years 5-6 of the simulation in (a) experiment WIND, (b) experiment FLUX, and (c) experiment FLUX_ATL. a)

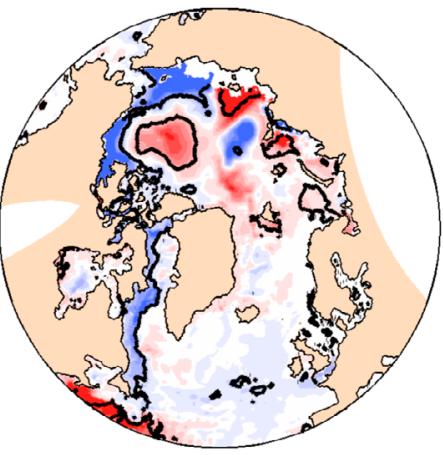

b)

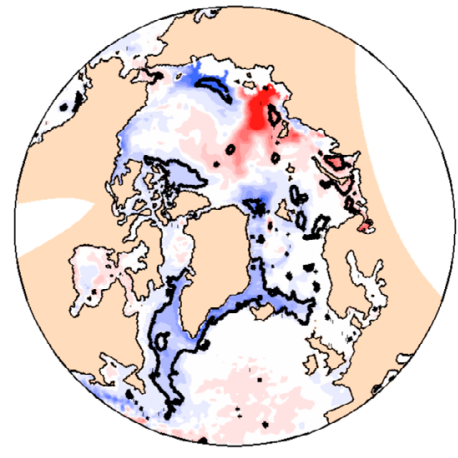

c)

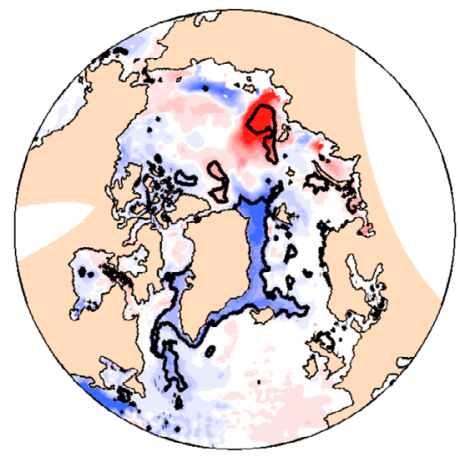

$-0.13-0.09-0.05-0.010 .030 .070 .11$

Figure 17. Simultaneous regression of the salinity at $30 \mathrm{~m}$ on (a) the freshwater flux through the CAA, (b) the ice volume transport through Fram Strait, and (c) the liquid freshwater flux through Fram Strait. All regressions performed on annual mean values over the period 1958-2001 and shown for enhanced outflows to the North Atlantic. The bold black contour indicates the $95 \%$ level of significance. 
a)

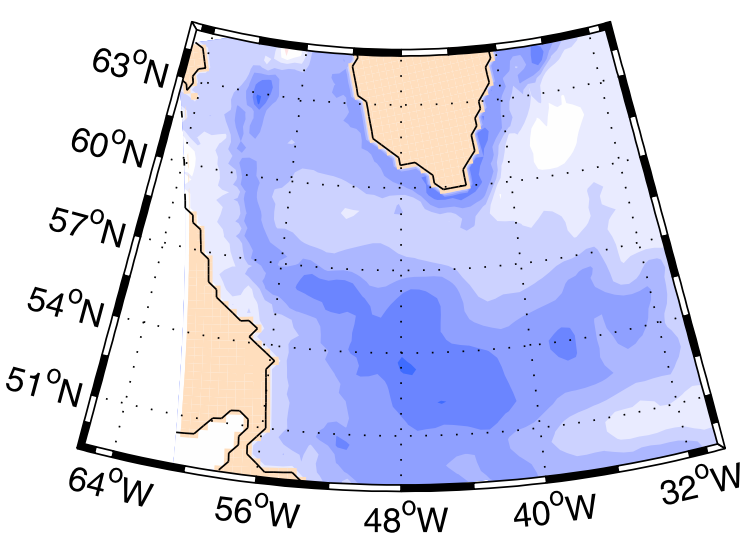

b)

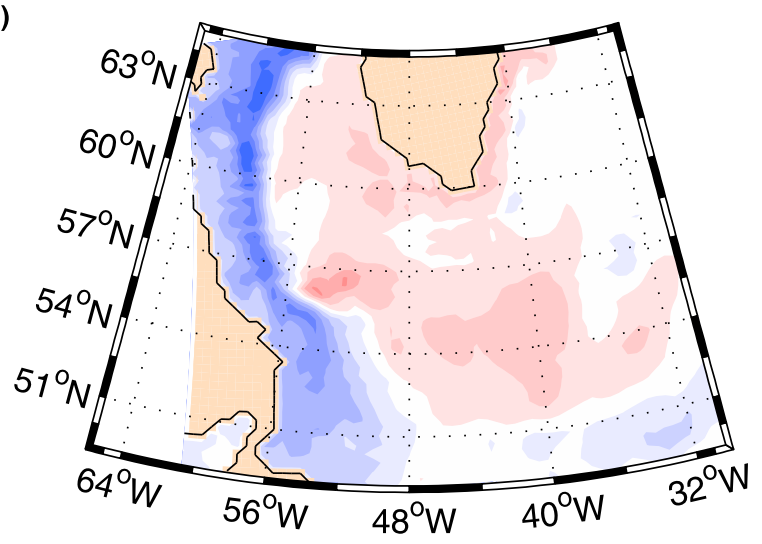

$\begin{array}{lllllll}-0.13-0.09 & -0.05 & -0.01 & 0.03 & 0.07 & 0.11\end{array}$

Figure 18. (a) First and (b) third EOF of the salinity at $30 \mathrm{~m}$.

that the northward propagation of the SSH anomalies proceeds from a wave response rather than an advective one.

\section{Impact on the Western North Atlantic Subpolar Gyre}

[32] Beyond the mechanisms forcing the CAA outflow variability, it is interesting to analyze the fate of this freshwater source in the North Atlantic and its possible impact on the subpolar gyre variability. Past observations have revealed recurrent signals of surface freshwater anomalies, known as Great Salinity Anomalies (GSA), in the North Atlantic subpolar gyre [Dickson et al., 1988; Belkin, 2004]. In particular, the drastic reduction of the convection at the end of $60 \mathrm{~s}$ and beginning of the 70s [Lazier, 1980] was attributed to the GSA which traveled through the subpolar gyre in the period 19681982 and passed through the Labrador Sea between 1969 and 1972. It has been suggested that some of these GSAs are triggered by large sea ice export events [Aagaard and Carmack, 1989; Häkkinen, 1993] or events of enhanced liquid freshwater outflow [Karcher et al., 2005] through the Fram Strait. To analyze the respective impacts of the Fram Strait sea ice export and CAA freshwater outflow on the salinity in the upper layer of the subpolar gyre, we performed a regression of the surface salinity on the CAA freshwater outflow based on the results of our hindcast experiment. The salinity distribution corresponding to enhanced outflow is characterized by a negative anomaly along the Labrador coast with little signal in the interior Labrador Sea (Figure 17a). When the same regression is performed on the sea ice export through Fram Strait, a totally different picture emerges. In response to an increase in the sea ice export, negative salinity anomalies form along the Greenland coast, which are seen all the way from Fram Strait to Davis Strait and, in contrast to anomalies related to the CAA, penetrate after a year into the interior Labrador Sea (Figure 17b). A similar response is obtained when the regression is performed onto the liquid freshwater export (Figure 17c) or the total (solid plus liquid) freshwater export (not shown). The solid and liquid components of the freshwater export are indeed well correlated $(\mathrm{r}=0.59$ ), contributing $84 \%$ and $74 \%$ of the variance of the total freshwater export, respectively. It is worth noting that the variability in the central Labrador Sea has weaker connection to the Fram Strait export compared with the surroundings. This result suggests that the upper salinity in the interior Labrador Sea would be also sensitive to other mechanisms than the Arctic freshwater exports, most probably related to changes in the local stratification through winter convection.

[33] The similarity between each of the two regression patterns shown in Figures 17c and 17a, and the first and third EOF of the upper salinity in the Labrador Sea (Figures 18a and 18b), respectively, is striking and suggests that the freshwater exports through Fram Strait and the CAA are responsible for distinct modes of surface salinity variability in the subpolar gyre. The first mode dominates the interior Labrador Sea variability and is mainly related to the Fram Strait sea ice export while the third mode has a signature confined on the Labrador shelf and is mainly controlled by the CAA freshwater outflow with little impact on the interior Labrador Sea variability.

\section{Discussion}

[34] Based on a linear regression analysis performed on the results of a hindcast experiment covering the period 1958 2001, we have been able to identify statistical links between the annual freshwater outflow through the CAA and the winter atmospheric forcing. Similar links are obtained when using an annual average of the forcing fields instead of a winter average, confirming the dominant influence of the winter atmospheric variability on this outflow. The regression patterns have much in common with the response obtained in sensitivity experiments in which the same model is forced by NAO-like atmospheric forcing fields. These similarities confirm that the variability identified in the hindcast experiment is consistent with an ocean response mainly driven by the NAO, a conclusion already drawn in other modeling studies. In our hindcast experiment, the maximum correlation of 0.48 between the winter NAO index and the total volume 
transport through the CAA obtained when the NAO leads by 1 year, is close to the 1 year lagged correlation of 0.54 reported by Jahn et al. [2010a] for the period 1948-2007, or to the simultaneous correlation of 0.43 reported by Koenigk et al. [2007] for the period 1950-2000. The statistical relationship to the NAO identified in the hindcast experiment inclined us to use dedicated NAO sensitivity experiments to highlight the mechanisms underpinning this relationship, to identify their link to the different components of the forcing and to provide a quantification of their relative impact on the CAA outflow.

[35] Results of our hindcast experiment and of our NAO sensitivity experiments all agree that part of the freshwater transport through the CAA is linked to the wind driven variability associated with the NAO in the western Arctic Ocean. Such a link was already mentioned in earlier studies that have emphasized the predominant role of the arctic atmospheric circulation on the freshwater export through the Archipelago. Proshutinsky et al. [2002] suggested that when a cyclonic wind forcing prevails in the western Arctic Ocean, the storage of freshwater in the Beaufort Gyre is reduced and the transport of freshwater to the North Atlantic is enhanced. Moreover, in agreement with the results of our sensitivity experiments to the $\mathrm{NAO}$, some of these earlier studies have also highlighted the particular role of the NAO in the above mechanism. Using a model forced by winds representative of extreme positive NAO conditions, Condron et al. [2009] found an increase of the freshwater export through both the CAA and Fram Strait which was mainly linked to a depletion of the freshwater storage in the Beaufort Gyre. In our sensitivity experiment, we observe a similar increase of the CAA freshwater outflow, though with typical variations of this outflow 3-4 times greater than in Condron et al.'s [2009] experiment.

[36] Using historical data as well as recent data collected from 2003 to 2008, Proshutinsky et al. [2009] suggested that variations of the Ekman pumping are mostly responsible for the variations of the freshwater content of the Beaufort Gyre on seasonal to decadal time scales. On the other hand, the causal link between the arctic atmospheric circulation and the outflow through the CAA is usually explained through a redistribution of the Beaufort Gyre freshwater reservoir driven by changes in the Ekman circulation. Considering that the freshwater storage in the Beaufort Gyre must have a strong signature in the SSH distribution, these results are consistent with our findings that the western Arctic SSH anomalies which drive the CAA outflow are largely determined by the wind stress. The regression of the SSH on the wind stress curl at the center of the Beaufort Gyre (not shown) indeed exhibits a distribution very similar to the SSH regression on the McClure velocity index shown in Figure 9a. The wind stress curl and the Ekman circulation in the Beaufort Sea control both the intensity of the Beaufort Gyre and the amount of water accumulated on the Beaufort Sea shelf. Still, our analysis provides a more detailed description of the impact of the arctic wind stress on the CAA outflow. Rather than being directly forced by the SSH variations which occur in the center of the Beaufort Gyre, we show that the wind driven variability of the CAA outflow is more complex and proceeds from a regional reorganization of the $\mathrm{SSH}$ gradient immediately to the west of McClure Strait. This local reorganization is connected to the formation of velocity anomalies which mostly affect the upper slope current surrounding the Canada Basin and therefore modulate the anticlockwise circulation of the basin. Still, rather than the changes in the intensity of the gyre circulation, it is the changes in the along-shelf SSH gradient west of McClure Strait which directly controls the amount of water which is being drawn from the basin interior onto the shelf and then into the strait. In this respect, the above mechanism resembles the scenario proposed by Newton et al. [2008] to explain the progression of the freshwater through the CAA during the course of a 20 year long simulation. It however differs somewhat from Jahn et al.'s [2010a] analysis which rather concludes that it is the SSH difference between the Beaufort Sea and the Baffin Bay, controlled to a large extent by the upstream SSH anomalies in the Beaufort Sea, which drives the variability of the CAA outflow. Our analysis shows that in the western Arctic, the distribution of SSH anomalies associated with the variability of the flow in McClure Strait has a maximum signal in the northern Canada Basin, that is in a region shifted to the north relative to the center of action of the wind stress curl in the Beaufort Sea. This is consistent with the fact that the SSH response in the center of the Beaufort Gyre does not correlate with the velocity anomalies in McClure Strait. The dynamical reasons for such a shift are still to be elucidated but our results already suggest that the SSH variability in the Canada Basin is more complex than a simple modulation of a wind-driven gyre, partly because of the existence of strong bottom topography gradients and non uniform stratification. A full understanding of the detailed features of this response would require further analyses using dedicated idealized experiments.

[37] We also show that the reorganization of the SSH gradients north of the CAA mainly affects the outflow to Lancaster Sound. Consistently, the upstream cross-strait SSH gradient in the western channel correlates at more than 0.7 with the water outflow to Lancaster Sound in our hindcast experiment while the along-strait SSH difference only correlates at 0.53 with the outflow (Figure 4). By contrast, the correlation of the along-strait gradient is much higher with the outflow through Nares Strait $(\mathrm{r}=0.9)$. Based on a diagnostic model of the CAA, Kliem and Greenberg [2003] draw similar conclusions, suggesting that Nares Strait is the most sensitive of the three passages of the CAA to the elevation difference from the Arctic Ocean to Baffin Bay. This type of information is hardly accessible using models with coarser resolutions. Coupled models with resolution on the order of $1^{\circ}$, in which the CAA is represented as a single channel with a geometry similar to the western channel of the archipelago, have been used by Jahn et al. [2010a, 2010b]. While Jahn et al. [2010a] found the along-strait gradient explains $46 \%$ of the variance of the velocity in the CAA, in agreement with the variance contributed by the western channel in our analysis, Jahn et al. [2010b] found this gradient explains as much as $82 \%$ of the variance. Moreover, the relative influence of the upstream and downstream SSH variability differs between the two studies, the SSH in the Beaufort Sea (resp. Baffin Bay) controlling most of the outflow variability in the former (resp. latter) study. These different behaviors can perhaps be explained by the different model physics (UVic ESCM model is used in the former study, CCSM3 model in the latter one) 
and their ability to represent those local patterns of the arctic SSH variability which have been shown to impact distinctly on the two main channels of the CAA. The above discrepancies would be consistent with the CAA behaving more like a "western channel equivalent" in Jahn et al.'s [2010a] study and more like a "Nares Strait equivalent" in Jahn et al.'s [2010b] study. Reasons for these discrepancies are however to be understood.

[38] Previous work on the dynamics of the CAA outflow did not conclude definitely on the relative impact of the Beaufort Sea SSH anomalies and Baffin Bay SSH anomalies on the along-strait gradient variability and ultimately on the transport through the CAA (note for instance the different conclusions of Jahn et al. [2010a] and Jahn et al. [2010b]). Our regression analysis helps clarifying this aspect as it shows that the variability in the two passages of the CAA in fact proceeds from two distinct mechanisms. While the western passage appears to be more sensitive to the wind driven $\mathrm{SSH}$ variations in the Arctic (Figure 9a), the eastern one responds preferentially to the downstream SSH variations in Smith Sound (Figure 4b). According to our analysis these downstream SSH variations are remotely forced by the air-sea heat fluxes over the Labrador Sea (Figure 12). Our NAO sensitivity experiments further provide quantification of the relative influence of the wind stress and the air-sea heat flux on the two passages. Although in positive NAO conditions the increase of the outflow has similar magnitude in Lancaster Sound and Nares Strait, there is a strong asymmetry between the two channels in terms of the response to the two components of the forcing. While the western channel only contributes $1 / 3$ of the buoyancy driven increase of the total CAA outflow, the Nares Strait roughly contributes $1 / 3$ of the wind-driven increase of the total outflow. Analyzing the $\mathrm{SSH}$ anomalies in our sensitivity experiments it was also possible to follow some of these anomalies along the western Greenland shelf as they were propagating northward from their formation region in the Labrador Sea to Smith Sound (not shown).

[39] The first EOF mode of variability of the upper salinity in the Labrador Sea has been shown to be related to the variability of the freshwater export through Fram Strait. With regards to the Labrador Sea convection, it is certainly the most important as it can modulate the interior basin stratification during the preconditioning phase. This mode should be compared with the GSA mode documented in the literature which, according to our model results would be almost exclusively driven by the export through Fram Strait. This result is in contrast to Belkin's [2004] suggestion that some GSAs may originate in Baffin Bay in response to the Canadian Arctic outflow. It is however in agreement with Haak et al.'s [2003] simulation results which suggest that the GSAs should be driven by events of excess ice export through Fram Strait, or with Myers's [2005] results. Prescribing freshwater fluxes to the north of Davis Strait in an eddy-permitting model of the Labrador Sea, Myers shows that these fluxes have little influence on the freshwater content of the interior Labrador Sea. In particular, only 6-8\% of the volume of a passive tracer injected at the northern boundary of his model appears to penetrate the interior of the basin, most of the tracer flowing southwest along the Labrador coast. A similar behavior was found by Houghton and Visbeck [2002]. Analyzing historical observations, they emphasize the influence of the freshwater flux from Baffin Bay on the freshwater content along the Labrador coast which could double during GSA events. Additionally, they suggest that eddy fluxes have the potential to transfer part of the freshwater accumulated on the Labrador shelf to the interior of the Labrador Sea. Such transfers are indeed underrepresented in our coarse resolution model which does not resolve the eddy scale and therefore may overestimate the tendency of the freshwater flow to remain confined on the Labrador shelf.

[40] Comparison between Figures $17 \mathrm{c}$ and $17 \mathrm{a}$ and Figures $18 \mathrm{a}$ and $18 \mathrm{~b}$ suggests that the Fram Strait freshwater export and the CAA outflow are able to drive out of phase patterns of subpolar salinity variability. With regards to the response to the atmospheric forcing, the first mode of the upper salinity in the Labrador Sea does not display any significant correlation with the NAO at any lag, whereas the third mode is significantly $(0.48)$ correlated with the NAO when the latter leads by 1 year. These correlations are consistent with the fact that, in the hindcast simulation, the relation of the freshwater export through the CAA to the NAO is more robust than that of the freshwater export through Fram Strait. Indeed, if one considers the entire period of the simulation, neither the ice volume transport nor the liquid freshwater transport through Fram Strait correlate significantly with the NAO. Only does the ice transport show significant simultaneous correlation with the NAO (although not larger than 0.45 ) over the reduced period spanning after 1978, in agreement with earlier studies [Hilmer and Jung, 2000; Kwok and Rothrock, 1999]. A detailed analysis of the freshwater export through Fram Strait is beyond the scope of the present study. Judging however from earlier analyses, the relation of this export to the NAO is largely set up through forcing of (both ice and liquid water) velocity anomalies by the along-strait wind but these velocity anomalies provide only a part of the variance of the freshwater export. With regards to the variability of the liquid component, according to Jahn et al. [2010b], the driving SLP pattern indeed resembles more the arctic Vorticity Index defined by Dmitrenko et al. [2008] which controls the freshwater content anomalies exported through the strait (that is the contribution $\frac{-\bar{U} \boldsymbol{S}^{\prime}}{S_{\text {ref }}}$ to the transport). With regards to the ice volume export, our hindcast experiment shows that it is controlled to a large extent by advection of thickness anomalies (Figure 19). The latter component indeed contributes to more than $65 \%$ of the variance of the total ice export while the velocity driven component contributes slightly less than 50\%. The upwind distribution of arctic ice thickness anomalies in phase with the former contribution to the ice volume export is indeed different from the dipolar pattern characteristic of a response to the AO [e.g., Houssais et al., 2007] (Figure 20a). However, 2 years before positive ice thickness anomalies are seen in Fram Strait, a pattern of ice thickness anomaly emerges which bears some resemblance with this dipolar pattern in a negative phase of the AO (Figure 20b). The resemblance is more obvious when the regression is performed over 19782001 than over the entire simulation period. Consistently, the anticorrelation between the transport of ice thickness anomalies through Fram Strait and the NAO index 2 years earlier increases from -0.3 over the whole simulation period to -0.47 over 1978-2001. According to the thickness pattern in Figure 20b, the significant thick ice anomalies located in the Canada Basin would be advected to Fram Strait in 2 years 


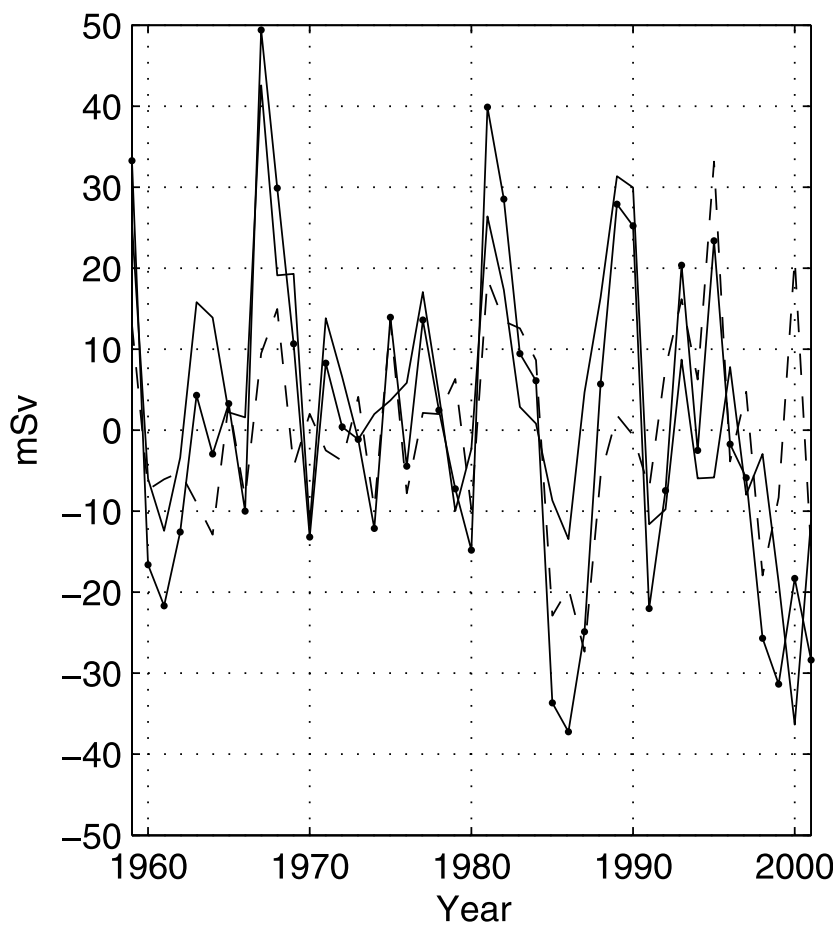

Figure 19. Mean annual sea ice volume transport anomaly (with regard to the 1958-2001 average, $\mathrm{mSv}$, solid line with dots) and the contributions due to transport of ice thickness anomalies by the mean velocity $\overline{\boldsymbol{u}}_{\boldsymbol{i}} h^{\prime}$ (solid line) and to anomalous transport of mean ice thickness $\boldsymbol{u}_{i}^{\prime} \bar{h}$ (dashed line) through Fram Strait.

a)

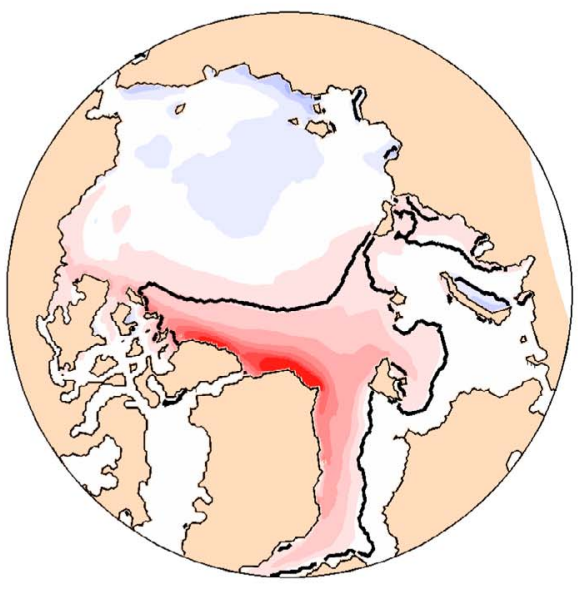

and contribute to enhance the ice export, a scenario also suggested by Haak et al. [2003]. Additionally, our result suggests that, under persistent NAO forcing, advection of arctic ice thickness anomalies through Fram Strait could after some years provide a feedback mechanism which would tend to stabilize the concomitant change of the ice volume transport due to enhanced ice drift anomalies in the strait. Our idealized positive NAO experiment indeed shows that advection of thinner ice occurs throughout the experiment which brings a negative (less volume exported to the Greenland Sea) contribution to the increase of the ice volume export under positive $\mathrm{NAO}$ forcing.

\section{Summary}

[41] An investigation of the link between the CAA freshwater outflow and the atmospheric forcing has been performed based on the joint analysis of a hindcast ice-ocean model experiment forced by the ERA40 reanalysis and the results of sensitivity experiments run with the same model forced by idealized NAO-like atmospheric forcing. The model domain covers the Arctic and the Atlantic Ocean and the horizontal grid allows the CAA to be represented by two distinct channels. The design of the sensitivity experiments has been motivated by the strong relationship identified between the variability of the water volume transport through the CAA (an excellent proxy of the variability of the freshwater outflow) and the NAO in the hindcast experiment.

[42] Earlier modeling studies dealing with the variability of the CAA outflow have stressed the particular role of the along-strait SSH gradients in this variability. Most of them, however, could not, or did not discriminate between
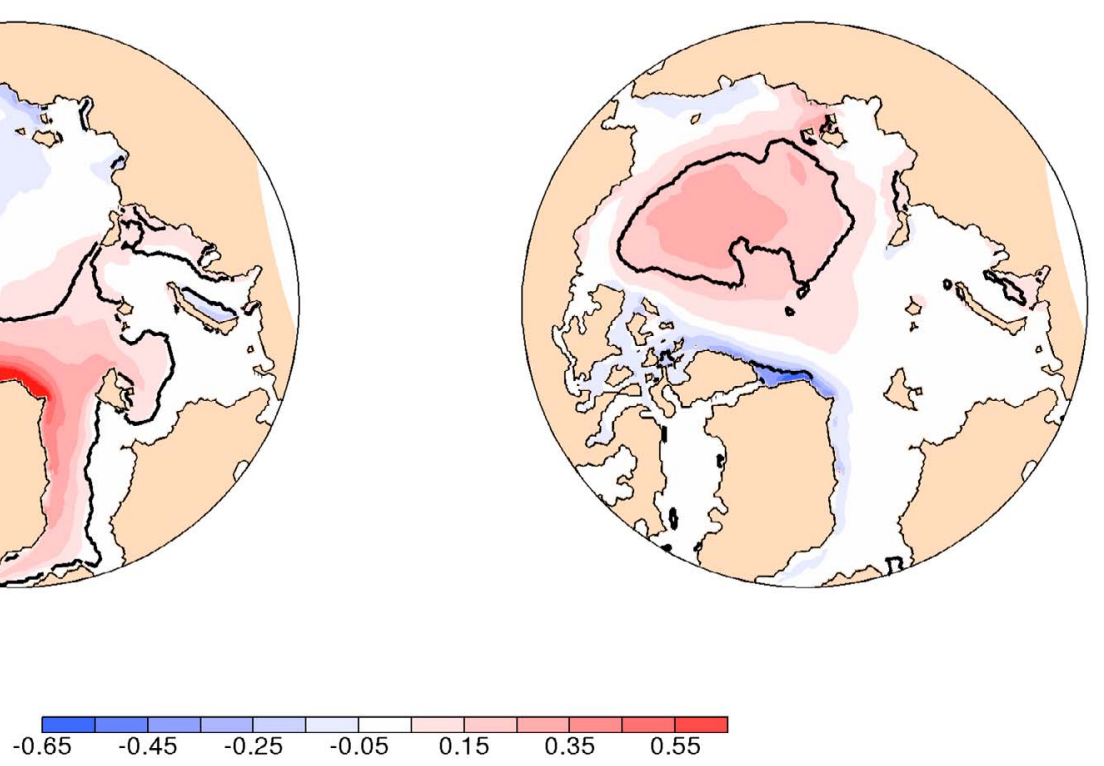

Figure 20. (a) Simultaneous and (b) 2 year lagged (ice thickness leads) regressions of the sea ice thickness anomalies $(\mathrm{m})$ on the contribution due to advection of ice thickness anomalies to the ice volume transport through Fram Strait (Figure 19, solid line). All regressions performed on annual mean values over the period 1958-2001 and shown for enhanced outflow to the North Atlantic. 
the behaviors of the different CAA channels or between the responses of these channels to the different components (dynamic and thermodynamic) of the atmospheric forcing. Our study confirms the sensitivity of the CAA outflow to the SSH distribution on either side (upstream and downstream) of the channels. However, it also brings out new conclusions regarding the contrasted behavior of the two channels in response to the atmospheric forcing. In particular, we show that the outflow through the western channel is less sensitive to the along-channel SSH gradient than the eastern outflow. Additionally, the western channel responds to a large extent to variations of the upstream (in McClure Strait) cross-strait SSH gradient, which is mostly controlled by the wind stress variability in the western Arctic. By contrast, the eastern channel reveals to be more sensitive to the along-channel $\mathrm{SSH}$ gradient, and more strongly to the downstream variations of the SSH in the northern Baffin Bay, the latter being remotely forced by air-sea heat flux anomalies in the Labrador Sea. The SSH anomalies formed in the Labrador Sea are indeed shown to propagate to the northern Baffin Bay along the western Greenland shelf. All these mechanisms, especially the particular role of the regional $\mathrm{SSH}$ distribution upstream of the CAA or that of the air-sea heat flux in the subpolar gyre on the variability of the outflow, had not been emphasized so far.

[43] The NAO has been shown to exert a strong control on the outflow through the CAA, a conclusion already drawn in earlier studies [e.g., Jahn et al., 2010a]. In particular the $\mathrm{NAO}$ is responsible for coherent variability between the two channels of the archipelago. Still, our analysis brings out new insights on the various mechanisms involved in this control. In particular, it is shown that, by increasing both the wind stress curl in the Beaufort Gyre and the ocean surface heat loss in the western subpolar gyre, positive NAO indices act to enhance the export of freshwater through the CAA. Still, the two mechanisms are not necessarily concomitant. While the wind stress generates a fast response of the export, the heat flux is shown to trigger a delayed (by about a year) response.

[44] In view of the above conclusions, it is conceivable that, in periods of positive NAO, the concomitant intensification of the Labrador Sea convection be partially offset by events of enhanced freshwater outflow through the CAA. The pattern of salinity anomalies linearly related to the occurrence of such events in our non eddy resolving simulation however suggests that the exported freshwater remains confined to the Labrador shelf with little impact on the interior convection region. The latter indeed appears to be predominantly influenced by events of ice or liquid freshwater exports through Fram Strait which propagates around Greenland in the form of "GSA-type" anomalies.

[45] The large-scale SSH distribution in the Arctic is known to be largely related to the freshwater storage, in particular to the Beaufort Gyre reservoir in the western Arctic. According to our analysis, the distribution of SSH anomalies impacting on the CAA outflow does not show such a strong signal in the Beaufort Gyre, suggesting that there is not a simple relationship between the variability of the CAA outflow and that of the Arctic freshwater reservoir.

[46] Acknowledgments. The authors wish to thank the two anonymous reviewers for their helpful comments which greatly improved the qual- ity of the manuscript. The above research has received funding from the European Community 7th Framework Programme through the THOR (Thermohaline Overturning - at Risk) project (2008-2012) under grant agreement GA212643. The authors also acknowledge support from the French Institut du Développement et des Ressources en Informatique Scientifique (IDRIS) which provided the necessary computing resources. This work has been carried out during the course of the AOMIP (Arctic Ocean Modeling Intercomparison Project) project.

\section{References}

Aagaard, K., and E. C. Carmack (1989), The role of sea ice and other fresh water in the Arctic circulation, J. Geophys. Res., 94, 14,485-14,498, doi:10.1029/JC094iC10p14485.

Agnew, T., A. Lambe, and D. Long (2008), Estimating sea ice area flux across the Canadian Artic Archipelago using enhanced AMSR-E, J. Geophys. Res., 113, C10011, doi:10.1029/2007JC004582.

Belkin, I. M. (2004), Propagation of the "Great Salinity Anomaly" of the 1990s around the northern North Atlantic, Geophys. Res. Lett., 31, L08306, doi:10.1029/2003GL019334.

Condron, A., P. Winsor, C. Hill, and D. Menemenlis (2009), Simulated response of the arctic freshwater budget to extreme NAO wind forcing, J. Clim., 22, 2422-2437, doi:10.1175/2008JCLI2626.1.

Cuny, J., P. B. Rhines, and R. Kwok (2005), Davis Strait volume, freshwater and heat fluxes, Deep Sea Res. Part I, 52, 519-542, doi:10.1016/j. dsr.2004.10.006.

Deser, C. (2000), On the teleconnectivity of the "Arctic Oscillation," Geophys. Res. Lett., 27, 779-782, doi:10.1029/1999GL010945.

de Steur, L., E. Hansen, R. Gerdes, M. Karcher, E. Fahrbach, and J. Holfort (2009), Freshwater fluxes in the East Greenland Current: A decade of observations, Geophys. Res. Lett., 36, L23611, doi:10.1029/ 2009GL041278

Dickson, R. R., J. Meincke, S.-A. Malmberg, and A. J. Lee (1988), The "Great Salinity Anomaly" in the northern North Atlantic 1968-1982, Prog. Oceanogr., 20, 103-151, doi:10.1016/0079-6611(88)90049-3.

Dickson, R. R., B. Rudels, S. Dye, M. Karcher, J. Meincke, and I. Yashayaev (2007), Current estimates of freshwater flux through Arctic and subarctic seas, Prog. Oceanogr., 73, 210-230, doi:10.1016/j. pocean.2006.12.003.

Dmitrenko, I. A., S. A. Kirillov, and L. B. Tremblay (2008), The long-term and interannual variability of summer fresh water storage over the eastern Siberian shelf: Implication for climatic change, J. Geophys. Res., 113, C03007, doi:10.1029/2007JC004304.

Haak, H., J. Jungclaus, U. Mikolajewicz, and M. Latif (2003), Formation and propagation of great salinity anomalies, Geophys. Res. Lett., 30(9), 1473, doi:10.1029/2003GL017065.

Häkkinen, S. (1993), An Arctic source for the Great Salinity Anomaly: Simulation of the Arctic ice ocean system for 1955-1975, J. Geophys. Res., 98, 16,397-16,410, doi:10.1029/93JC01504

Herbaut, C., and M.-N. Houssais (2009), Response of the eastern North Atlantic subpolar gyre to the North Atlantic Oscillation, Geophys. Res. Lett., 36, L17607, doi:10.1029/2009GL039090.

Hilmer, M., and T. Jung (2000), Evidence for a recent change in the link between the North Atlantic Oscillation and Arctic Sea ice export, Geophys. Res. Lett., 27, 989-992, doi:10.1029/1999GL010944.

Houghton, R. W., and M. H. Visbeck (2002), Quasi-decadal salinity fluctuations in the Labrador Sea, J. Phys. Oceanogr., 32, 687-701, doi:10.1175/1520-0485(2002)032<0687:QDSFIT>2.0.CO;2.

Houssais, M.-N., C. Herbaut, P. Schlichtholz, and C. Rousset (2007), Arctic salinity anomalies and their link to the North Atlantic during a positive phase of the Arctic Oscillation, Prog. Oceanogr., 73, 160 189, doi:10.1016/j.pocean.2007.02.005.

Hurrell, J. W., and H. van Loon (1997), Decadal variations associated with the North Atlantic Oscillation, Clim. Change, 36, 301-326, doi:10.1023/ A: 1005314315270 .

Jahn, A., B. Tremblay, L. A. Mysak, and R. Newton (2010a), Effect of the large scale atmospheric circulation on the variability of the Arctic Ocean freshwater export, Clim. Dyn., 34, 201-222, doi:10.1007/s00382-009. 0558-Z

Jahn, A., B. Tremblay, R. Newton, M. M. Holland, L. A. Mysak, and I. A. Dmitrenko (2010b), A tracer study of the Arctic Ocean's liquid freshwater export variability, J. Geophys. Res., 115, C07015, doi:10.1029/ 2009JC005873.

Jungclaus, J. H., H. Haak, M. Latif, and U. Latif (2005), Arctic-North Atlantic interactions and multidecadal variability of the meridional overturning circulation, J. Clim., 18, 4013-4031, doi:10.1175/JCLI3462.1.

Karcher, M., R. Gerdes, F. Kauker, C. Köberle, and I. Yashayaev (2005), Arctic Ocean heralds North Atlantic freshening, Geophys. Res. Lett., 32, L21606, doi:10.1029/2005GL023861. 
Kliem, N., and D. A. Greenberg (2003), Diagnostic simulations of the summer circulation in the Canadian Arctic Archipelago, Atmos. Ocean, 41, 273-289, doi:10.3137/ao.410402.

Köberle, C., and R. Gerdes (2007), Simulating variability of the Arctic Ocean freshwater balance 1948-2001, J. Phys. Oceanogr., 37, 16281644, doi:10.1175/JPO3063.1.

Koenigk, T., U. Mikolajewicz, H. Haak, and J. Jungclaus (2007), Arctic freshwater export in the 20th and 21ST centuries, J. Geophys. Res., 112, G04S41, doi:10.1029/2006JG000274.

Kwok, R. (2005), Variability of Nares Strait ice flux, Geophys. Res. Lett., 32, L24502, doi:10.1029/2005GL024768.

Kwok, R. (2009), Outflow of Arctic ocean sea ice into the Greenland and Barents seas: 1979-2007, J. Clim., 22, 2438-2457, doi:10.1175/ 2008JCLI2819.1.

Kwok, R., and D. A. Rothrock (1999), Variability of Fram Strait ice flux and the North Atlantic Oscillation, J. Geophys. Res., 104, 5177-5189, doi:10.1029/1998JC900103.

Large, W. G., and S. G. Yeager (2004), Diurnal to decadal global forcing for ocean and sea-ice models: The data sets and flux climatologies, Tech. Note NCAR/TN-460+STR, Clim. and Global Dyn. Div., Natl. Cent. for Atmos. Res., Boulder, Colo.

Lazier, J. R. N. (1980), Oceanographic conditions at Ocean Weather Ship Bravo 1964-1974, Atmos. Ocean, 18, 227-238.

Lique, C., A.-M. Tréguier, M. Scheinert, and T. Penduff (2009), A modelbased study of ice and freshwater transport variability along both sides of Greenland, Clim. Dyn., 33, 685-705, doi:10.1007/s00382-008-0510-7.

Madec, G. (2008), "NEMO ocean engine," Note Pôle Modél. 27, Inst. Pierre Simon Laplace, Paris.

Melling, H., T. A. Agnew, K. K. Falkner, D. A. Greenberg, C. M. Lee, A. Münchow, B. Petrie, S. J. Prinsenberg, R. M. Samelson, and R. A. Woodgate (2008), Fresh-water fluxes via Pacific and Arctic outflows across the Canadian Polar shelf, in Arctic-Subarctic Ocean Fluxes, edited by R. R. Dickson et al., pp. 193-247, doi:10.1007/978-1-4020-6774-7_10, Springer, New York.

Meredith, M., K. Heywood, P. Dennis, L. Goldson, R. White, E. Fahrbach, U. Schauer, and S. Østerhus (2001), Freshwater fluxes through the western Fram Strait, Geophys. Res. Lett., 28, 1615-1618, doi:10.1029/ 2000GL011992.

Münchow, A., and H. Melling (2008), Ocean current observations from Nares Strait to the west of Greenland: Interannual to tidal variability and forcing, J. Mar. Res., 66, 801-833.

Myers, P. G. (2005), Impact of freshwater from the Canadian Arctic Archipelago on Labrador Sea Water formation, Geophys. Res. Lett., 32, L06605, doi:10.1029/2004GL022082.

Newton, R., P. Schlosser, D. G. Martinson, and W. Maslowski (2008), Freshwater distribution in the Arctic Ocean: Simulation with a highresolution model and model-data comparison, J. Geophys. Res., 113, C05024, doi:10.1029/2007JC004111.

Prinsenberg, S. J., and J. Hamilton (2005), Monitoring the volume, freshwater and heat fluxes passing through Lancaster Sound in the Canadian Arctic Archipelago, Atmos. Ocean, 43, 1-22, doi:10.3137/ao.430101.
Proshutinsky, A., R. H. Bourke, and F. A. McLaughlin (2002), The role of the Beaufort Gyre in Arctic climate variability: Seasonal to decadal climate scales, Geophys. Res. Lett., 29(23), 2100, doi:10.1029/ 2002GL015847.

Proshutinsky, A., R. Krishfield, M.-L. Timmermans, J. Toole, E. Carmack, F. McLaughlin, W. J. Williams, S. Zimmermann, M. Itoh, and K. Shimada (2009), Beaufort Gyre freshwater reservoir: State and variability from observations, J. Geophys. Res., 114, C00A10, doi:10.1029/2008JC005104. Rigor, I., R. Colony, and S. Martin (2000), Variations in surface air temperature observations in the Arctic, 1979-1997, J. Clim., 13, 896-914, doi:10.1175/1520-0442(2000)013<0896:VISATO>2.0.CO;2.

Rossow, W. B., and R. A. Schiffer (1999), Advances in understanding clouds from ISCCP, Bull. Am. Meteorol. Soc., 80, 2261-2288, doi:10.1175/1520-0477(1999)080<2261:AIUCFI $>2.0 . C O ; 2$.

Schauer, U., A. Beszczynska-Möller, W. Walczowski, E. Fahrbach, J. Piechura, and E. Hansen (2008), Variation of measured heat flow through the Fram Strait between 1997 and 2006, in Arctic-Subarctic Ocean Fluxes, edited by R. R. Dickson et al., pp. 65-85, doi:10.1007/ 978-1-4020-6774-7 4, Springer, New York.

Schlichtholz, P., and M.-N. Houssais (1999), An inverse modeling study in Fram Strait. Part II: Water mass distribution and transports, Deep Sea Res. Part II, 46, 1137-1168, doi:10.1016/S0967-0645(99)00017-X. Serreze, M. C., A. P. Barrett, A. G. Slater, R. A. Woodgate, K. Aagaard, R. B. Lammers, M. Steele, R. Moritz, M. Meredith, and C. M. Lee (2006), The large-scale freshwater cycle of the Arctic, J. Geophys. Res., 111, C11010, doi:10.1029/2005JC003424.

Steele, M., R. Morley, and W. Ermold (2001), PHC: A global ocean hydrography with a high quality Arctic Ocean, J. Clim., 14, 20792087, doi:10.1175/1520-0442(2001)014<2079:PAGOHW>2.0.CO;2.

Tang, C., C. K. Ross, T. Yao, B. Petrie, B. M. DeTracey, and E. Dunlap (2004), The circulation, water masses and sea-ice of Baffin Bay, Prog. Oceanogr., 63, 183-228, doi:10.1016/j.pocean.2004.09.005.

Thompson, D. W. J., and J. M. Wallace (2000), Annular modes in the extratropical circulation. Part I: Month-to-month variability, J. Clim. 13, 1000-1016, doi:10.1175/1520-0442(2000)013<1000:AMITEC $>2.0$. $\mathrm{CO} ; 2$.

Uppala, S. M., et al. (2005), The ERA-40 re-analysis, Q. J. R. Meteorol Soc., 131, 2961-3012, doi:10.1256/qj.04.176.

Vinje, T., N. Nordlund, and Å. Kvambekk (1998), Monitoring ice thickness in Fram Strait, J. Geophys. Res., 103, 10,437-10,449, doi:10.1029/ 97JC03360.

Widell, K., S. Østerhus, and T. Gammelsrød (2003), Sea ice velocity in the Fram Strait monitored by moored instruments, Geophys. Res. Lett., 30(19), 1982, doi:10.1029/2003GL018119.

Yang, J., and J. C. Comiso (2007), An unexpected seasonal variability of salinity in the Beaufort Sea upper layer in 1996-1998, J. Geophys. Res., 112, C05034, doi:10.1029/2004JC002716.

C. Herbaut and M.-N. Houssais, LOCEAN, UMR 7159, CNRS/UPMC/ IRD/MNHN, Université Pierre et Marie Curie, Case 100, 4 place Jussieu, F-75252 Paris CEDEX 05, France. (mnh@locean-ipsl.upmc.fr) 